\title{
Spark Plasma Sintered NdFeB-based Nanocomposite Hard Magnets with Enhanced Magnetic Properties
}

\author{
N. Lupu, M. Grigoraş, M. Lostun and H. Chiriac \\ National Institute of Research and Development for Technical Physics, \\ Iasi, Romania
}

\section{Introduction}

Since the discovery of 2:14:1 permanent magnets (PMs) in the early 80 's, the nanocrystalline and nanocomposite RE-Fe-B PMs attracted extensive attention both from the academia and industry because of their enhanced magnetic performances and potential applications (Croat et al., 1984; Givord et al.., 1984; Hadjipanayis et al., 1984; Onodera et al., 1984; Yamauchi et al., 1985; Jha \& Davies, 1989; Pinkerton, 1991; Hadjipanayis, 1999; Liu et al., 2008; Fukagawa et al., 2010). Whereas the enhanced remanence and energy product of nanocrystalline NdFe-B PMs result from the exchange coupling between magnetically hard grains (Manaf et al., 1993), for the nanocomposite PMs the superior magnetic properties are the result of the fine mixture of $\mathrm{RE}_{2} \mathrm{Fe}_{14} \mathrm{~B}$ hard magnetic and Fe-based soft magnetic grains, which are exchange coupled (Kneller \& Hawig, 1991). Typically, the exchange coupling in nanophase magnets tends to reduce the coercivity (Mendoza-Suarez et al., 2000) and the energy product decreases with the volume fraction of the magnetic phase, which are well-known challenges in the processing of PMs. The recent work proved the important role played by magnetostatic interactions in the increase of the nucleation and coercive field values of nanocomposite permanent magnets in the detriment of the exchange coupled interactions (Gabay et al., 2006; Marinescu et al., 2008).

The properties of nanocomposite PMs are strongly influenced by a number of process parameters like the composition, preparation method, annealing conditions, distribution of soft and hard magnetic nanograins (Cui et al., 2005). The large values of the remanence are related to the strength of the exchange interactions between the soft and hard magnetic grains, thus the reduction of the grains below the size of the hard magnetic phase domain walls is essential, but they should not decrease below a critical value, dependent on the nanocomposite composition, which causes the reduction of the magnetocrystalline anisotropy of the hard magnetic phase and, consequently, the drastic decrease of the coercive field. Nanocomposite magnets are expected to have maximum energy products as high as 120 MGOe, when the soft and hard magnetic phases are arranged in the proper way and the exchange interactions optimized (Skomski \& Coey, 1993). However, the theoretical value of the maximum energy product of $\mathrm{NdFeB}$ magnets is calculated to be $512 \mathrm{~kJ} / \mathrm{m}^{3}(64$ MGOe) (Sagawa et al., 1985).

There are two principal manufacturing routes to prepare RE-TM-B nanocomposite PMs: (i) the classical powder metallurgy or sintered magnet process (Sagawa et al., 1984; Durst \& 
Kronmüller, 1987; Kaneko et al., 2006) and (ii) the rapid solidification or bonded magnet process (McGuiness et al., 1992a; McGuiness et al., 1992b; Tomka et al., 1995; Folks et al., 1995; Zhang \& Xiong, 2009). Sintered magnets are prepared from magnetically aligned powders into dense blocks, which are then heat treated, cut to shape, surface treated and magnetized. Bonded magnets are prepared from milled melt-spun ribbons mixed with a polymer or a resin and either compressed or injection moulded. The bonded magnets offer less flux than sintered ones but can be shaped into intricately shaped parts and their eddy current losses are significantly smaller. The melt-spun ribbons can be also hot pressed into fully dense isotropic magnets, and then forged or extruded into high energy anisotropic magnets.

About a decade ago a new technique appeared as an alternative to the conventional sintering methods. Spark Plasma Sintering (SPS) method can consolidate Nd-Fe-B powders at relatively lower temperatures in a short period of time, and the achieved densities of compacted materials can go up to 99\% (Liu et al., 1999; Saito, 2001; Ono et al., 2003). But the main and the most important advantage of SPS technique is the high sintering speed, which can effectively hinder the grains growth over the critical nanosize. However, the structure and properties of the compacted materials are dependent on several process parameters, such as the sintering temperature and the applied pressure.

In this following, we will present our results on the preparation and magnetic properties of a few types of Spark Plasma Sintered NdFeB-based nanocomposite magnets prepared from mixtures of ball-milled powders of stoichiometric and non-stoichiometric Nd-Fe-B nanocrystalline melt-spun ribbons and Fe-based amorphous and crystalline materials. The novelty, compared with the already published work on SPS nanocomposite magnets, consists of the use for the first time ever of Fe and Fe-Co- based amorphous/nanocrystalline materials as soft magnetic components.

\section{Nd-Fe-B melt spun ribbons}

Stoichiometric $\mathrm{Nd}_{12} \mathrm{Fe}_{82} \mathrm{~B}_{6}(\mathrm{Nd} 12)$, sub-stoichiometric $\mathrm{Nd}_{8} \mathrm{Fe}_{86} \mathrm{~B}_{6}$ (Nd8) and $\mathrm{Nd}_{10} \mathrm{Fe}_{84} \mathrm{~B}_{6}$ (Nd10), and $\mathrm{Nd}$-rich $\mathrm{Nd}_{15} \mathrm{Fe}_{79} \mathrm{~B}_{6}(\mathrm{Nd} 15)$ and $\mathrm{Nd}_{16} \mathrm{Fe}_{78} \mathrm{~B}_{6}$ (Nd16) master alloys have been prepared by arc melting using a mixture of pure elements in argon atmosphere. The alloys have been re-melted a few times for homogenization and used further to prepare amorphous and nanocrystalline ribbons having thicknesses of $25 \mu \mathrm{m}$ and widths of 3-5 mm by melt-spinning technique, as shown in Figs. 1 and 2. Whereas the Nd8 XRD pattern (Fig. 1) indicates only the presence of the $\mathrm{Fe}_{3} \mathrm{~B}$ peak superposed on the broad one of the amorphous phase, the $\mathrm{Nd} 10$ ribbon consists of a mixture of $\alpha \mathrm{Fe}, \mathrm{Fe}_{3} \mathrm{~B}$ and amorphous phase. The stoichiometric Nd12 melt-spun ribbons are nanocrystalline in the as-quenched state, but the size of the grains as determined by using the Scherrer formula is around $100 \mathrm{~nm}$, and the presence of the residual amorphous matrix is still present. The DSC curves shown in Fig. 2 indicate also the decrease of the amount of amorphous phase with the increase of the $\mathrm{Nd}$ content, and for samples with $\mathrm{Nd}$ content over 12 at.\% the amorphous phase contribution can not be observed anymore. Whilst the Nd-rich ribbons $\left(\mathrm{Nd}_{15} \mathrm{Fe}_{79} \mathrm{~B}_{6}\right.$ and $\left.\mathrm{Nd}_{16} \mathrm{Fe}_{78} \mathrm{~B}_{6}\right)$ have been further used in the as-quenched state as precursors to prepare powders by high-energy ball-milling, the stoichiometric $\mathrm{Nd}_{12} \mathrm{Fe}_{82} \mathrm{~B}_{6}$ and sub-stoichiometric $\mathrm{Nd}_{8} \mathrm{Fe}_{86} \mathrm{~B}_{6}$ and $\mathrm{Nd}_{10} \mathrm{Fe}_{84} \mathrm{~B}_{6}$ ones have been first annealed to achieve the optimum nanocrystalline structure and then ball-milled. 


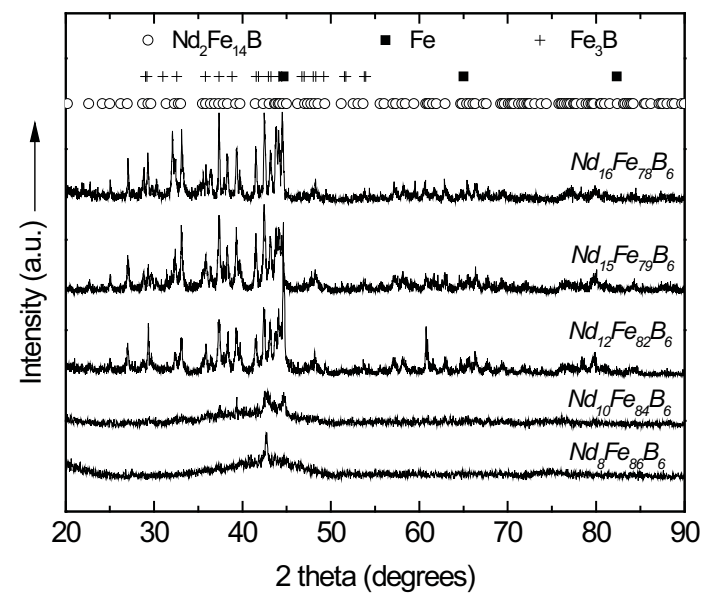

Fig. 1. XRD patterns of Nd-Fe-B melt-spun ribbons in the as-quenched state as a function of Nd content.

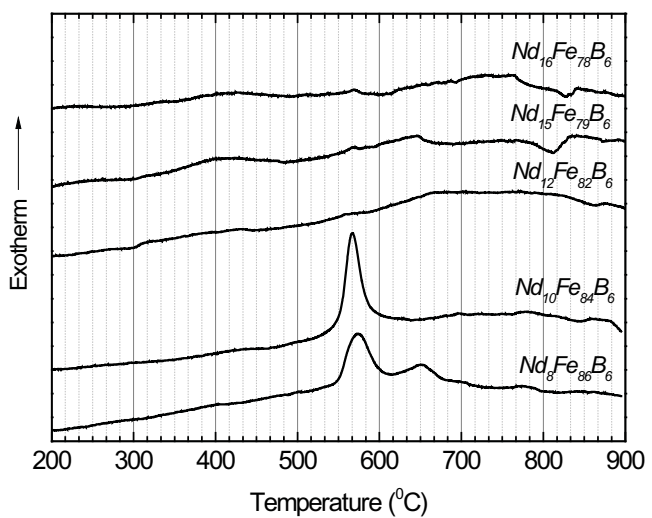

Fig. 2. DSC curves for Nd-Fe-B melt-spun ribbons vs. Nd content.

The variation of the magnetic characteristics of $\mathrm{Nd} 8, \mathrm{Nd} 10$ and $\mathrm{Nd} 12$ melt-spun ribbons as a function of annealing temperature and time are shown in Fig. 3 and Table 1. The coercive field increases with the increase of the $\mathrm{Nd}$ content as the result of the increase of the amount of 2:14:1 hard magnetic phase, which in the same time causes a slight decrease of the saturation magnetization and remanence. The coercive field of $\mathrm{Nd} 8$ ribbons starts increasing with the annealing temperature, when the 2:14:1 and $\mathrm{Fe}_{3} \mathrm{~B}$ phases are precipitating. The further increase of the annealing temperature keeps the coercive field almost constant in the temperature range $610-650^{\circ} \mathrm{C}$ and then starts decreasing slowly due to the increase of the soft magnetic grains. For Nd10 melt-spun ribbons, the presence of $\alpha \mathrm{Fe}$ and $\mathrm{Fe}_{3} \mathrm{~B}$ phases in the as-quenched state results only in the very slight variation of the magnetic characteristics, whereas for the already nanocrystalline Nd12 melt-spun ribbons in the as-quenched state the annealing is refining the nanograins structure and consequently the coercive field increases whereas the saturation magnetization and remanence remain almost unchanged. From Fig. 3 one can conclude that the optimum annealing temperature is $630^{\circ} \mathrm{C}$ for $\mathrm{Nd} 8$ and $\mathrm{Nd} 10$ melt-spun ribbons, and $610^{\circ} \mathrm{C}$ for $\mathrm{Nd} 12$ melt-spun ribbons, respectively. 


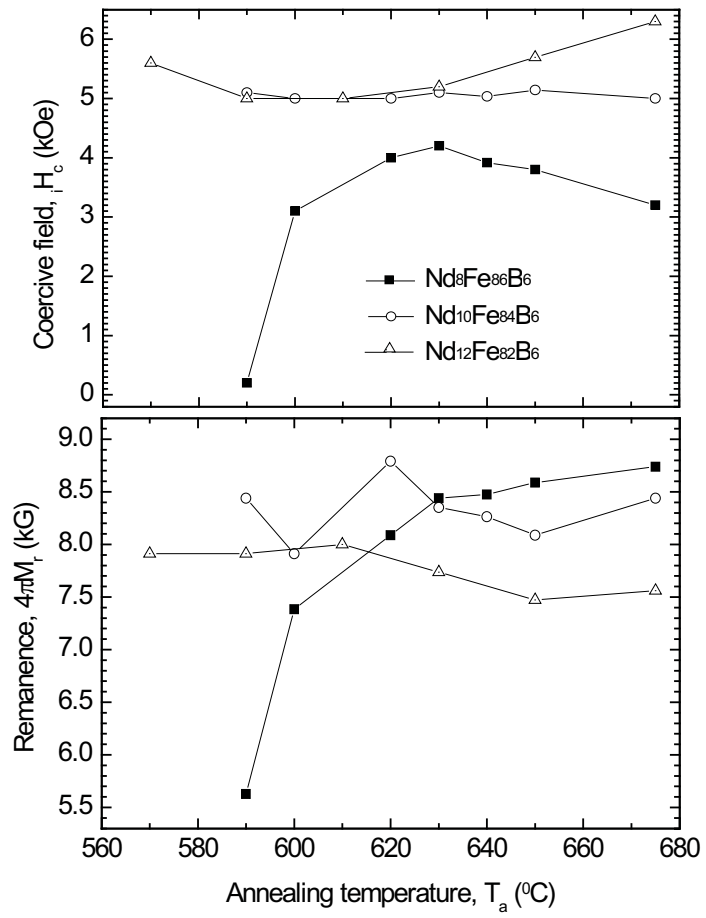

Fig. 3. The variation of the coercive field and remanence as a function of the annealing temperature $\left(\mathrm{T}_{\mathrm{a}}\right)$ for $\mathrm{Nd} 8, \mathrm{Nd} 10$ and $\mathrm{Nd} 12$ melt-spun ribbons.

Keeping the annealing temperature constant we varied the annealing time and the obtained results are given in Table 1.

\begin{tabular}{|c|c|c|c|c|c|}
\hline Composition & Annealing time (min.) & ${ }_{i} \mathbf{H}_{\mathbf{c}}(\mathbf{k O e})$ & $\mathbf{4 \pi} \mathbf{M}_{\mathbf{s}}(\mathbf{k G})$ & $\mathbf{4} \boldsymbol{\pi} \mathbf{M}_{\mathbf{r}}(\mathbf{k G})$ & $\mathbf{M}_{\mathbf{r}} / \mathbf{M}_{\mathbf{s}}$ \\
\hline \multirow{2}{*}{$\begin{array}{c}\mathrm{Nd}_{8} \mathrm{Fe}_{86} \mathrm{~B}_{6} \\
\left(\mathrm{~T}_{\mathrm{a}}=630^{\circ} \mathrm{C}\right)\end{array}$} & 10 & 3.6 & 13.2 & 7.6 & 0.57 \\
\cline { 2 - 6 } & 20 & 4.2 & 13.1 & 8.4 & 0.63 \\
\hline \multirow{2}{*}{\begin{tabular}{c}
$\mathrm{Nd}_{10} \mathrm{Fe}_{84} \mathrm{~B}_{6}$ \\
\cline { 2 - 6 }$\left(\mathrm{T}_{\mathrm{a}}=630^{\circ} \mathrm{C}\right)$
\end{tabular}} & 30 & 2.8 & 13.1 & 7.8 & 0.60 \\
\cline { 2 - 6 } & 10 & 5.0 & 11.3 & 8.6 & 0.75 \\
\hline \multirow{2}{*}{\begin{tabular}{c}
$\mathrm{Nd}_{12} \mathrm{Fe}_{82} \mathrm{~B}_{6}$ \\
\cline { 2 - 6 }$\left(\mathrm{T}_{\mathrm{a}}=610^{\circ} \mathrm{C}\right)$
\end{tabular}} & 20 & 5.2 & 11.7 & 8.4 & 0.72 \\
\cline { 2 - 6 } & 30 & 5.0 & 11.0 & 8.1 & 0.73 \\
\cline { 2 - 6 } & 20 & 5.0 & 11.8 & 8.0 & 0.73 \\
\hline
\end{tabular}

Table 1. Magnetic characteristics of Nd-Fe-B melt-spun ribbons vs. annealing time.

The increase of the annealing time from 10 to $20 \mathrm{~min}$. for $\mathrm{Nd} 8$ melt-spun ribbons enhances the magnetic characteristics because of the achievement of the full nanocrystalline structure. The further increase of the $T_{a}$ to $30 \mathrm{~min}$. produces the decoupling of the soft and hard magnetic nanograins due to the increase over the critical size of the soft magnetic nanograins. Due to the already existing nanocrystalline structure in the as-quenched state, 
the annealing of the $\mathrm{Nd} 12$ melt-spun ribbons at $610^{\circ} \mathrm{C}$ for $10 \mathrm{~min}$. is enough to refine the nanograins structure and to increase the number of exchange interactions. By increasing even further the annealing time the nanograins are growing excessively and the magnetic properties are altered. The magnetic characteristics of the Nd10 melt-spun ribbons are not changing significantly with the annealing time modification, most probably because of the precipitation in the as-quenched state of soft magnetic $\alpha \mathrm{Fe}$ and $\mathrm{Fe}_{3} \mathrm{~B}$ phases.

\section{Nd-Fe-B powders}

$\mathrm{Nd}-\mathrm{Fe}-\mathrm{B}$ melt-spun ribbons have been cut in small pieces and then ball-milled in 2 stainless steel vials with 15 stainless steel balls in each vial. It is well known that the characteristics of the sintered magnets are strongly dependent on the magnetic characteristics of the ballmilled powders. The resulting Nd-Fe-B powders have sizes ranging from 20 to $100 \mu \mathrm{m}$. We've noticed that by increasing the milling time the magnetic properties of the powders are deteriorating. This behaviour could have 2 distinct causes: (1) easier oxidation of the powders when they are becoming smaller for longer milling times (despite the fact that milling is done in protective atmosphere), and (2) the precipitation of more Fe-based soft magnetic phase(s) in the detriment of 2:14:1 hard magnetic phase. To minimize the effect of the magnetic characteristics alteration the melt-spun ribbons were milled only for 4 min. $\mathrm{Nd}-\mathrm{Fe}-\mathrm{B}$ powders, and especially those with larger contents of $\mathrm{Nd}(\geq 12$ at.\%), are very brittle, so smaller milling times can provide the powders in the desired range of sizes. In Table 2 are presented comparatively the magnetic characteristics for stoichiometric and substoichimoetric Nd-Fe-B melt-spun ribbons and the resulting ball-milled powders with sizes ranging from 20 to $100 \mu \mathrm{m}$.

\begin{tabular}{|c|c|c|c|c|}
\hline Composition & Sample type & ${ }_{\mathbf{i}} \mathbf{H}_{\mathbf{c}}(\mathbf{k G})$ & $\mathbf{4} \boldsymbol{\pi} \mathbf{M}_{\mathbf{s}}(\mathbf{k G})$ & $\mathbf{4} \pi \mathbf{M}_{\mathbf{r}}(\mathbf{k G})$ \\
\hline \multirow{2}{*}{$\mathrm{Nd}_{8} \mathrm{Fe}_{86} \mathrm{~B}_{6}$} & Melt-spun ribbon & 4.2 & 13.2 & 8.4 \\
\cline { 2 - 5 } & Powders & 4.3 & 12.0 & 7.3 \\
\hline \multirow{2}{*}{$\mathrm{Nd}_{10} \mathrm{Fe}_{84} \mathrm{~B}$} & Melt-spun ribbon & 5.0 & 11.9 & 8.9 \\
\cline { 2 - 5 } & Powders & 5.2 & 11.0 & 7.5 \\
\hline \multirow{2}{*}{$\mathrm{Nd}_{12} \mathrm{Fe}_{82} \mathrm{~B}_{6}$} & Melt-spun ribbon & 6.3 & 11.2 & 8.4 \\
\cline { 2 - 5 } & Powders & 7.7 & 10.3 & 6.6 \\
\hline
\end{tabular}

Table 2. Magnetic characteristics for annealed melt-spun ribbons and the resulting powders.

One can notice the increase of the coercive field and the slight decrease of the saturation magnetization and remanence for the resulting powders. The increase of the coercive field is more pronounced for the powders with larger Nd contents, most probably as a result of the decoupling between the soft and hard magnetic phases, as shown in Fig. 4. For Nd8 and Nd10 powders the exchange coupling is improved (the shoulder in the second quadrant disappears) compared with the precursor melt-spun ribbons, confirming the previously observed results for milled powders used to make bonded magnets (McGuiness et al., 1992a; McGuiness et al., 1992b; Tomka et al., 1995; Folks et al., 1995; Zhang \& Xiong, 2009). A consequence of better exchange coupling between the soft and hard magnetic grains is also the small reduction of the remanence for $\mathrm{Nd} 8$ and $\mathrm{Nd} 10$ ball-milled powders. It is important to note also that the magnetization hysteresis loop for Nd12 powders is not saturated, but clearly shows the presence of 3 magnetic phases: soft magnetic $\alpha \mathrm{Fe}$ and $\mathrm{Fe}_{3} \mathrm{~B}$ and hard magnetic 2:14:1 phase, whereas the melt-spun ribbons consist only of $\alpha$ Fe soft magnetic and 2:14:1 hard magnetic phase. 

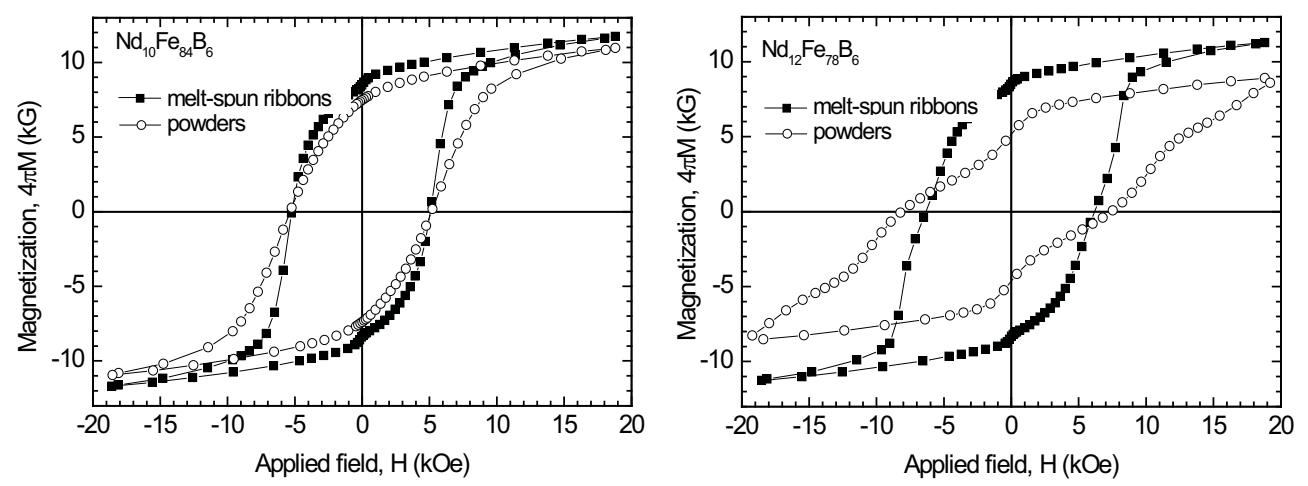

Fig. 4. Magnetic hysteresis curves for $\mathrm{Nd} 10$ and $\mathrm{Nd} 12$ annealed melt-spun ribbons (at $630^{\circ} \mathrm{C}$ for $20 \mathrm{~min}$. for $\mathrm{Nd} 10$ and $610^{\circ} \mathrm{C}$ for $10 \mathrm{~min}$. for Nd12), respectively, and the resulting ballmilled powders with sizes ranging from 20 to $100 \mu \mathrm{m}$.

Fig. 5 presents the hysteresis loops for $\mathrm{Nd}_{15} \mathrm{Fe}_{79} \mathrm{~B}_{6}$ melt-spun and ball-milled powders of 63$80 \mu \mathrm{m}$ as well as for $\mathrm{Nd}_{16} \mathrm{Fe}_{78} \mathrm{~B}_{6}$ melt-spun and powders in the range size of 80-100 $\mu \mathrm{m}$.
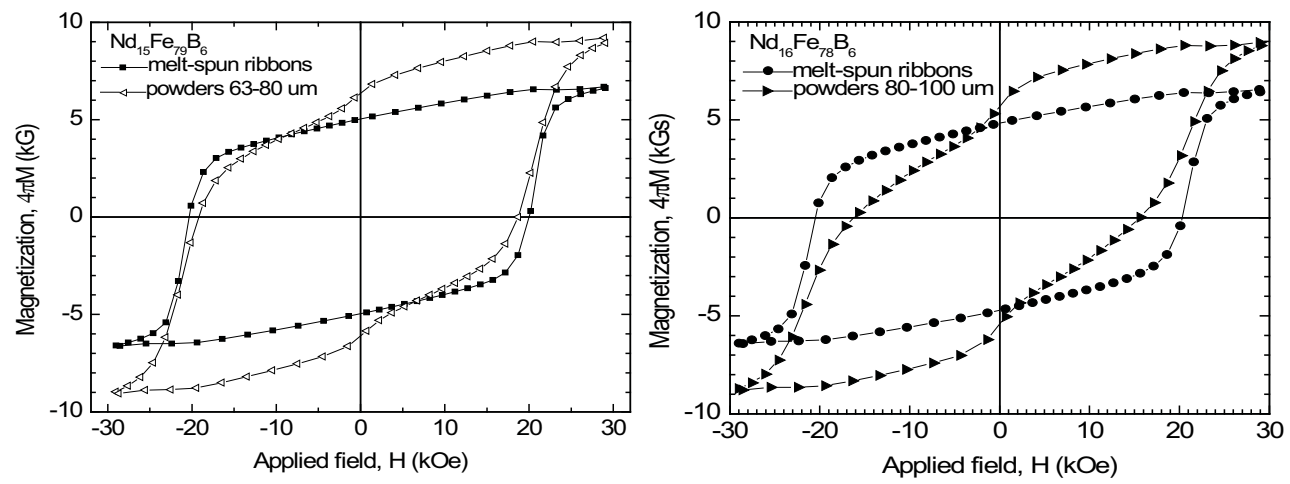

Fig. 5. Magnetic hysteresis curves for $\mathrm{Nd} 15$ and $\mathrm{Nd} 16$ as-quenched melt-spun ribbons and the resulting ball-milled powders with sizes ranging from 63 to $100 \mu \mathrm{m}$.

As one can see the hysteresis curves of powders are constricted compared with the meltspun ribbon's ones, which might be an indication that during ball-milling the precipitation of more Fe-based phases is favoured in the detriment of 2:14:1 phase and the decoupling is more evident. Additionally, the magnetic behaviour of Nd-rich alloys powders is strongly dependent on the powders size compared with the stoichiometric and sub-stoichiometric compositions for which we didn't notice such a behaviour. The optimum magnetic properties are achieved for $\mathrm{Nd} 15$ powders in the 63-80 $\mu \mathrm{m}$ range and respectively for $\mathrm{Nd} 16$ powders with sizes between 80 and $100 \mu \mathrm{m}$, as shown in Fig. 6. Most probably, this behaviour is a collective process which involves both the surface oxidation effects (despite the fact that the ball-milling is done in protective Ar atmosphere) and the grains size refinement. It is worthwhile to note the high values of the coercive field obtained for both $\mathrm{Nd} 15$ and $\mathrm{Nd} 16$ melt-spun nanocrystalline ribbons and ball-milled powders of about or over $20 \mathrm{kOe}$, but also the moderate values of the remanence which are a clear proof that the 
predominant phase is 2:14:1, whereas the volume of Fe-based soft magnetic phases is much smaller compared with $\mathrm{Nd} 8, \mathrm{Nd} 10$ and $\mathrm{Nd} 12$ samples. One should also notice that the applied field of $3 \mathrm{~T}$ used in this work is not enough to saturate either the melt-spun ribbons or ball-milled powders.
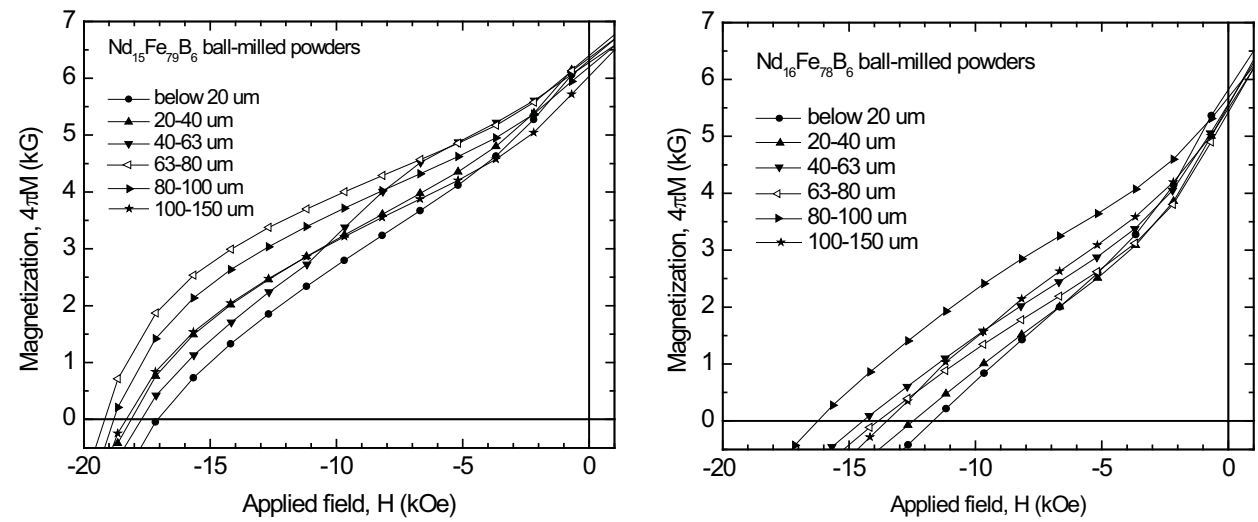

Fig. 6. Demagnetization curves for Nd15 and Nd16 ball-milled powders in the size range 10$150 \mu \mathrm{m}$.

\section{Soft magnetic materials used as precursors for SPS nanocomposite PMs}

For this study we have chosen a number of soft magnetic materials to be used as precursor for preparing SPS nanocomposite magnets: (1) $\mathrm{Fe}_{77.5} \mathrm{Si}_{7.5} \mathrm{~B}_{15}$ (FeSiB) $\left(4 \pi \mathrm{M}_{\mathrm{s}} \sim 16 \mathrm{kG}\right)$ and (2) $\mathrm{Co}_{68.25} \mathrm{Fe}_{4.5} \mathrm{Si}_{12.25} \mathrm{~B}_{15}(\mathrm{CoFeSiB})\left(4 \pi \mathrm{M}_{\mathrm{s}} \sim 8 \mathrm{kG}\right)$ conventional amorphous wires (CAW) of 100$125 \mu \mathrm{m}$ in diameter prepared by in-rotating water quenching method (Ohnaka, 1985; Vazquez \& Chen, 1995; Chiriac et al., 1998); (2) $\mathrm{Co}_{68.2} \mathrm{Fe}_{4.45} \mathrm{Mn}_{0.1} \mathrm{Si}_{12.25} \mathrm{~B}_{15}$ (CoFeMnSiB) amorphous melt-spun ribbons $\left(4 \pi \mathrm{M}_{\mathrm{s}} \sim 8 \mathrm{kG}\right)$ (Hilzinger \& Kunz, 1980; Makino et al., 1990; Chiriac et al., 1997); (3) $\mathrm{Fe}_{73.5} \mathrm{Nb}_{3} \mathrm{CuSi}_{13.5} \mathrm{~B}_{9}$ (FINEMET) nanocrystalline melt-spun ribbons $\left(4 \pi \mathrm{M}_{\mathrm{s}} \sim 12.4 \mathrm{kG}\right)$ (Yoshizawa et al., 1988); (4) $\mathrm{Fe}_{2}$ Co crystalline melt-spun ribbons $\left(4 \pi \mathrm{M}_{\mathrm{s}} \sim 22\right.$ $\mathrm{kG})$; and (5) commercial Fe micropowders $\left(4 \pi \mathrm{M}_{\mathrm{s}} \sim 20 \mathrm{kG}\right)$ of about $10 \mu \mathrm{m}$. The studies done up to know on Nd-Fe-B nanocomposite bulk magnets (sintered or bonded) used either Fe (Wei et al., 1994; McCormick et al., 1998; Lewis et al., 2001; Rada et al., 2005; Niu et al., 2007; Bhame et al., 2010; Cha et al., 2010) or $\mathrm{Fe}_{2} \mathrm{Co}$ micro or nanopowders (Wei et al., 1994) to increase the remanence and saturation magnetization of the respective PMs, whereas $\mathrm{Fe}, \mathrm{Fe}-$ $\mathrm{Co}$ and $\mathrm{Fe}-\mathrm{B}$ have been used in combination with $\mathrm{Nd}-\mathrm{Fe}-\mathrm{B}$ to prepare multilayered structures by deposition methods (Shindo et al., 1996; Cui \& O'Shea, 2004; Ao et al., 2005; Kato et al., 2005). Additionally, other attempts to prepare nanocomposite PMs used combinations of Nd-Fe-B and Sm-Co-based particles (Talijan, 2006; Betancourt \& Davies, 2010). However, excepting the multilayered structures obtained by deposition, most of the other studies are related to nanocomposite magnets prepared by milling of the starting $\mathrm{Nd}$ Fe-B alloys followed by mixing with Fe-based soft magnetic materials and then annealing of the full composite, and not by milling the melt-spun ribbons in the as-quenched state or after annealing. Our goal is to use soft magnetic high saturation magnetization materials in combination with Nd-Fe-B ball milled powders. 
FeSiB and CoFeSiB CAW have been cut in small pieces and then ball-milled in argon atmosphere for $6 \mathrm{~h}$. The resulting micropowders have sizes between 5 and $150 \mu \mathrm{m}$, and their magnetic properties are almost independent of the powders size (Fig. 7) compared with NdFe-B ball milled powders. The amorphous state is preserved even after milling for $6 \mathrm{~h}$, as shown by the structural studies.
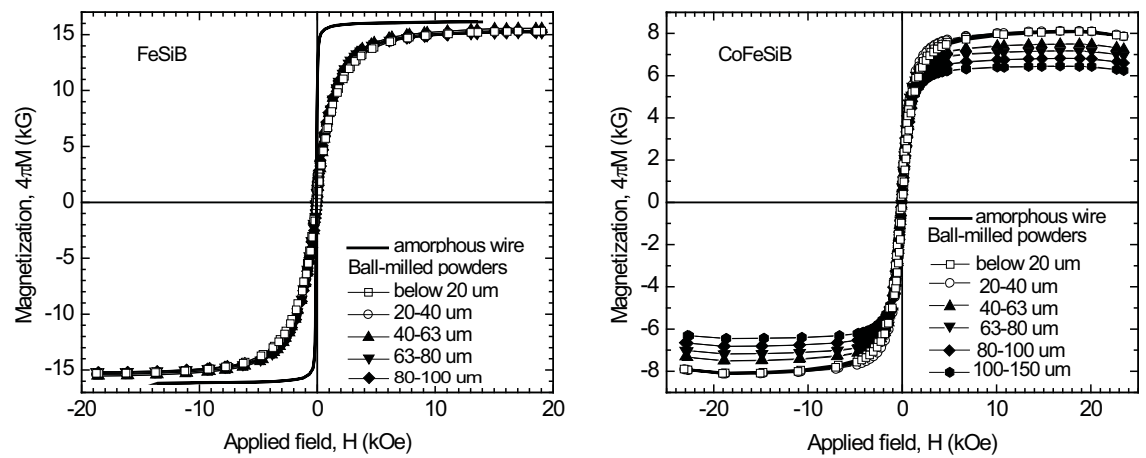

Fig. 7. Magnetic hysteresis curves for FeSiB and CoFeSiB as-quenched conventional amorphous wires (CAW) and the resulting ball-milled powders.

The same behaviour was observed for amorphous CoFeMnSiB and FINEMET powders prepared from amorphous and respectively nanocrystalline melt-spun ribbon precursors. The amorphous FINEMET ribbons have been annealed at $560^{\circ} \mathrm{C}$ for $1 \mathrm{~h}$ to achieve the optimum $\alpha$ Fe nanograins size $(\sim 10 \mathrm{~nm})$ and then ball-milled for $20 \mathrm{~h}$. The same milling time was used to prepare powders from CoFeMnSiB amorphous ribbons. After milling the nanocrystalline structure of FINEMET ribbons and respectively the amorphous structure of CoFeMnSiB melt-spun ribbons are preserved, and the ball-milled powders show almost identical XRD patterns.

X-ray diffraction pattern of $\mathrm{Fe}_{2} \mathrm{Co}$ ( $\mathrm{FeCo}$ ) melt-spun ribbons of $25 \mu \mathrm{m}$ thick prepared by melt-spinning reveals only the bcc lines. The same structure is preserved after ball-milling the ribbons for $24 \mathrm{~h}$. The magnetic characteristics measured for the precursor melt-spun ribbons and ball-milled powders are almost similar, with saturation magnetization of about $22 \mathrm{kG}$.

The commercial Fe micropowders of $10 \mu \mathrm{m}$ used in this study to prepare SPS nanocomposite magnets have a saturation magnetization of $\sim 20 \mathrm{kGs}$, a little bit lower than the saturation magnetization of bulk Fe $(\sim 22 \mathrm{kG})$, indicating the presence of some traces of Fe oxides on their surface as confirmed by XRD measurements (very small peaks corresponding to $\mathrm{Fe}_{2} \mathrm{O}_{3}$ can be identified along with the bcc lines of $\mathrm{Fe}$ ).

\section{Spark Plasma Sintered (SPS) nanocomposite magnets}

$\mathrm{Nd}-\mathrm{Fe}-\mathrm{B}$ and soft magnetic materials powders have been mixed in different ratios (80:20; 90:10; 92:8; 94:6; 95:5 and 96:4, respectively), placed into a carbon die, and then sintered under vacuum by SPS. The temperature of the specimen was increased from room 
temperature to the consolidating temperature of $600^{\circ} \mathrm{C}$ for $300 \mathrm{~s}$ and then held at the consolidating temperature for $300 \mathrm{~s}$ by applying a pulsed electric current of $800 \mathrm{~A}$ at intervals of $2.4 \mathrm{~ms}$. The temperature was measured using a thermocouple placed on the surface of the sample. The specimens have been prepared at different pressures ranging from 50 to $80 \mathrm{MPa}$, applied during the heating. After the SPS consolidation, the samples have been cooled down to room temperature without applying pressure. The specimens were $10 \mathrm{~mm}$ in diameter and $2-5 \mathrm{~mm}$ in thickness. Their structural and magnetic properties have been investigated afterwards by means of X-ray diffractometry (BRUKER AXS D8ADVANCE XRD), scanning electron microscopy combined with EDS (Carl Zeiss CrossBeam Neon 40 EsB), and vibrating sample magnetometry (LakeShore 7410 VSM).

Fig. 8 shows the XRD patterns for a number of $\mathrm{Nd}-\mathrm{Fe}-\mathrm{B} /$ soft magnetic material SPS nanocomposite magnets. One can notice that after spark plasma sintering the 2:14:1 phase is preserved and additional peaks corresponding to $\alpha \mathrm{Fe}(\mathrm{Co})$ and $\mathrm{Fe}_{3} \mathrm{~B}$ soft magnetic phases can be easily identified. However, the amount of soft magnetic phases is larger compared with the Nd-Fe-B melt-spun precursors due to the supplementary addition of Fe and Co-Fe based soft magnetic materials. As smaller the amount of $\mathrm{Nd}$ in the precursor $\mathrm{Nd}-\mathrm{Fe}-\mathrm{B}$ powders, as larger the amount of 2:14:1 phase is, contrary to the expectations. This means the addition of soft magnetic powders is contributing to the precipitation of a larger amount of 2:14:1 phase in the nanocomposite samples.

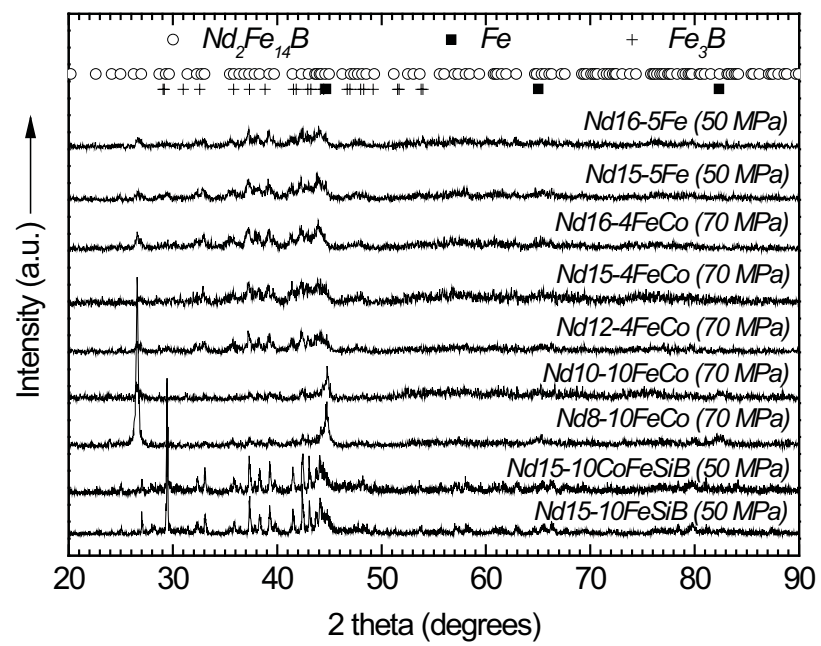

Fig. 8. XRD patterns of Nd-Fe-B/soft magnetic powders SPS nanocomposite magnets.

The formation of a larger amount of 2:14:1 hard magnetic phase is also demonstrated by the thermomagnetic curves presented in Fig. 9. It is worth noticing that the largest saturation magnetization is achieved for $\mathrm{Nd} 12-4 \mathrm{FeCo}$ SPS nanocomposites and also a significant increase is observed for all $\mathrm{Nd}-\mathrm{Fe}-\mathrm{B} / \mathrm{FeCo}$ nanocomposite samples as expected. The presence of $\alpha \mathrm{Fe}$ is observed for all nanocomposite samples $\left(\mathrm{T}_{\mathrm{C}} \sim 770^{\circ} \mathrm{C}\right)$ and the largest amount of soft magnetic $\alpha \mathrm{Fe}$ is present in $\mathrm{Nd}-\mathrm{Fe}-\mathrm{B} / \mathrm{Fe}$ magnets. 

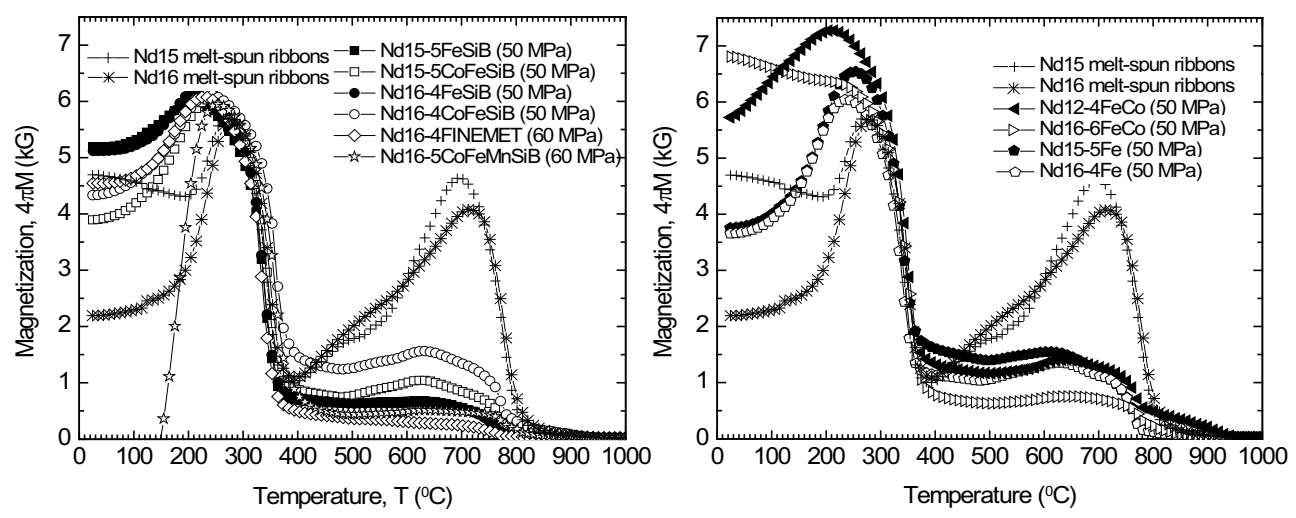

Fig. 9. M-T curves for Nd-Fe-B/soft magnetic powders SPS nanocomposite magnets. The thermomagnetic curves for $\mathrm{Nd} 15$ and $\mathrm{Nd} 16$ melt-spun ribbons are shown for comparison.

The values of the magnetic characteristics for several Nd-Fe-B/FeSiB and Nd-Fe-B/CoFeSiB nanocomposite magnets prepared by SPS are shown in Table 3.

\begin{tabular}{|c|c|c|c|}
\hline Sample & $4 \pi M_{r}(k G)$ & ${ }_{\mathrm{i}} \mathbf{H}_{\mathrm{c}}(\mathrm{kOe})$ & $(\mathrm{BH})_{\max }$ (MGOe) \\
\hline \multicolumn{4}{|l|}{$\mathrm{Nd}_{15} \mathrm{Fe}_{79} \mathrm{~B}_{6}$} \\
\hline Melt-spun ribbons & 5.0 & 20.30 & $6.2(25.4)$ \\
\hline Ball-milled powders $(63-80 \mu \mathrm{m})$ & 6.3 & 19.01 & $9.9(29.9)$ \\
\hline NdFeB-4FeSiB / $70 \mathrm{MPa}$ & 5.8 & 16.02 & $8.4(23.2)$ \\
\hline NdFeB-5FeSiB / $50 \mathrm{MPa}$ & 6.5 & 17.85 & $10.6(29.0)$ \\
\hline NdFeB-10FeSiB / $50 \mathrm{MPa}$ & 5.9 & 16.97 & $8.7(25.0)$ \\
\hline NdFeB-5CoFeSiB / $50 \mathrm{MPa}$ & 6.2 & 17.45 & $9.6(27.0)$ \\
\hline NdFeB-10CoFeSiB / $50 \mathrm{MPa}$ & 5.4 & 15.13 & $7.3(20.4)$ \\
\hline \multicolumn{4}{|l|}{$N d_{16} F_{78} B_{6}$} \\
\hline Melt-spun ribbons & 4.82 & 20.44 & $5.8(24.6)$ \\
\hline Ball-milled powders $(80-100 \mu \mathrm{m})$ & 5.70 & 16.17 & $8.1(23.0)$ \\
\hline NdFeB-4FeSiB / $50 \mathrm{MPa}$ & 6.27 & 17.41 & $9.9(27.3)$ \\
\hline NdFeB-5FeSiB / $50 \mathrm{MPa}$ & 5.87 & 16.97 & $8.7(24.9)$ \\
\hline NdFeB-4CoFeSiB / $50 \mathrm{MPa}$ & 6.11 & 17.41 & $9.3(26.6)$ \\
\hline NdFeB-5CoFeSiB / $50 \mathrm{MPa}$ & 5.99 & 17.02 & $9.0(25.5)$ \\
\hline
\end{tabular}

Table 3. The magnetic characteristics of several Nd-Fe-B/FeSiB and Nd-Fe-B/CoFeSiB nanocomposite magnets prepared by SPS method, as a function of the hard to soft materials ratio and the applied pressure during consolidation. The $(\mathrm{BH})_{\max }$ values in the brackets are calculated for a packing degree of $98 \%$ (Lupu et al., 2009) and for an applied field of 50 kOe.

The largest coercive field is obtained for melt-spun ribbons, whilst the powders show larger values of the remanence. By consolidation through the SPS technique the maximum energy product generally increases for optimal processing parameters, the highest increase of about $10 \%$ being obtained for $\mathrm{Nd} 16-4 \mathrm{FeSiB}$ nanocomposite magnet consolidated at $50 \mathrm{MPa}$. The degree of compaction for the below mentioned samples is reaching $65 \%$, and if we extrapolate the data to an apparent density of $98 \%$ (Saito et al., 2004) and we assume the 
samples are saturated in an external field of $50 \mathrm{kOe}$ then the maximum energy product for our isotropic SPS nanocomposite magnets is reaching values of 25-29 MGOe, comparable with those obtained up to now for anisotropic nanocomposite magnets (Saito, 2001; Yue at al., 2003).

Fig. 10(a) presents comparatively the $\mathrm{dM} / \mathrm{dH}=\mathrm{f}(\mathrm{H})$ curves for $\mathrm{Nd} 15$ ball-milled powders and 2 SPS nanocomposite magnets (Nd15-5FeSiB and Nd15-5CoFeSiB), both consolidated at $50 \mathrm{MPa}$, whilst Fig. 10(b) shows the variation of $\mathrm{dM} / \mathrm{dH}$ with the soft magnetic material content for the same consolidating pressure.
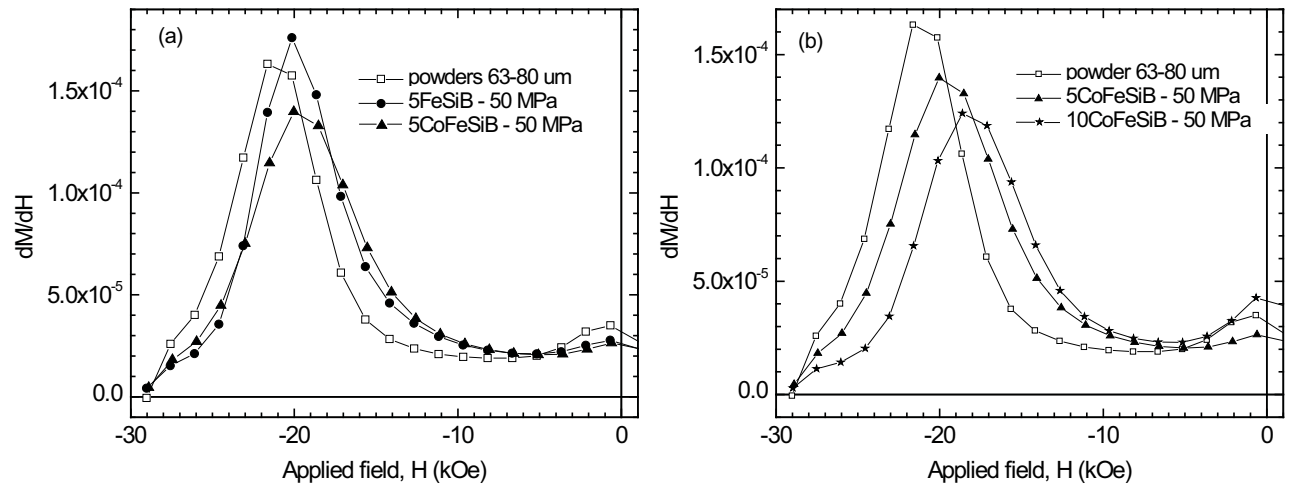

Fig. 10. $d M / d H=f(H)$ curves for Nd15 ball-milled powders and SPS consolidated nanocomposite magnets as a function of added soft magnetic material (Lupu et al., 2009).

One can notice that despite the fact that the powders exhibit larger coercive field, the coupling between the soft and hard magnetic phases is improved for nanocomposite magnets. The strength of the decoupling is indicated by the second shoulder of $\mathrm{dM} / \mathrm{dH}=\mathrm{f}(\mathrm{H})$ curves located nearby $\mathrm{Y}$ axis, which is very small for SPS consolidated nanocomposite magnets, but also by the height of the first peak. In this case, it is hard to believe that only the intergranular exchange coupling is responsible for such behaviour, but most probably a collective process of both exchange and magnetostatic interactions between the powders of the 2 materials forming the nanocomposite (Gabay et al., 2006).

The same behavior is observed for Nd16 powders and nanocomposite magnets, as indicated in Fig. 11. As expected, the exchange coupling plays the predominant role in melt-spun nanocrystalline ribbons and the presence of the second shoulder is missing, whereas for the composites the magnetostatic interactions becomes more predominant (see also Fig. 12). However, the percentage of exchange interactions contribution to the macroscopic response of the nanocomposite systems is still very important, considering that usually the magnetostatic interactions are reducing the coercive field values.

The maximum energy product increases with about $13 \%$ for $\mathrm{Nd} 15 /$ soft magnetic material and Nd16/soft magnetic material nanocomposite SPS magnets. The optimum sintering temperature is $50 \mathrm{MPa}$.

The interactions between the nanograins of SPS nanocomposite magnets were examined by using the $\delta \mathrm{M}$ plot, defined as:

$$
\delta M(H)=m_{d}(H)-\left[1-2 m_{r}(H)\right]
$$


where $m_{d}$ is the reduced demagnetization remanence and $m_{r}$ is the reduced isothermal remanence. According to Wohlfarth's model (Wohlfarth, 1958), a positive $\delta \mathrm{M}$ peak indicates an exchange coupling process, while a negative $\delta \mathrm{M}$ peak indicates magnetostatic interactions between the magnetically hard and soft phases. A sharp peak indicates strong exchange interactions between the constituent grains, and a less pronounced peak reveals weak exchange intergranular interactions.

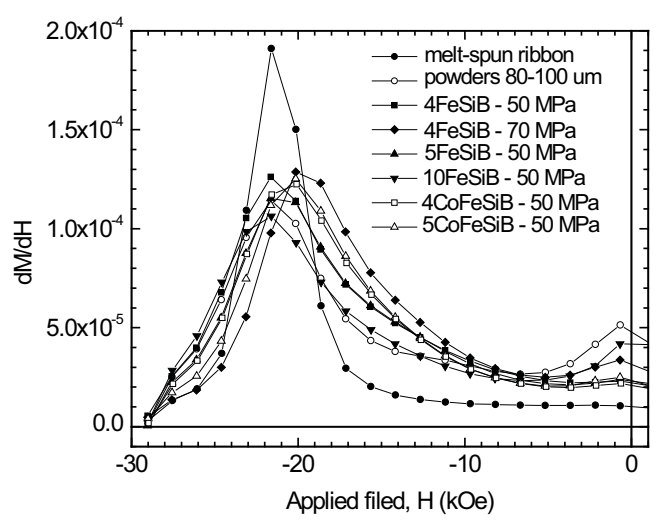

Fig. 11. $\mathrm{dM} / \mathrm{dH}=\mathrm{f}(\mathrm{H})$ curves for Nd16 melt-spun ribbons, ball-milled powders and SPS consolidated nanocomposite magnets as a function of added soft magnetic material (Lupu et al., 2009).
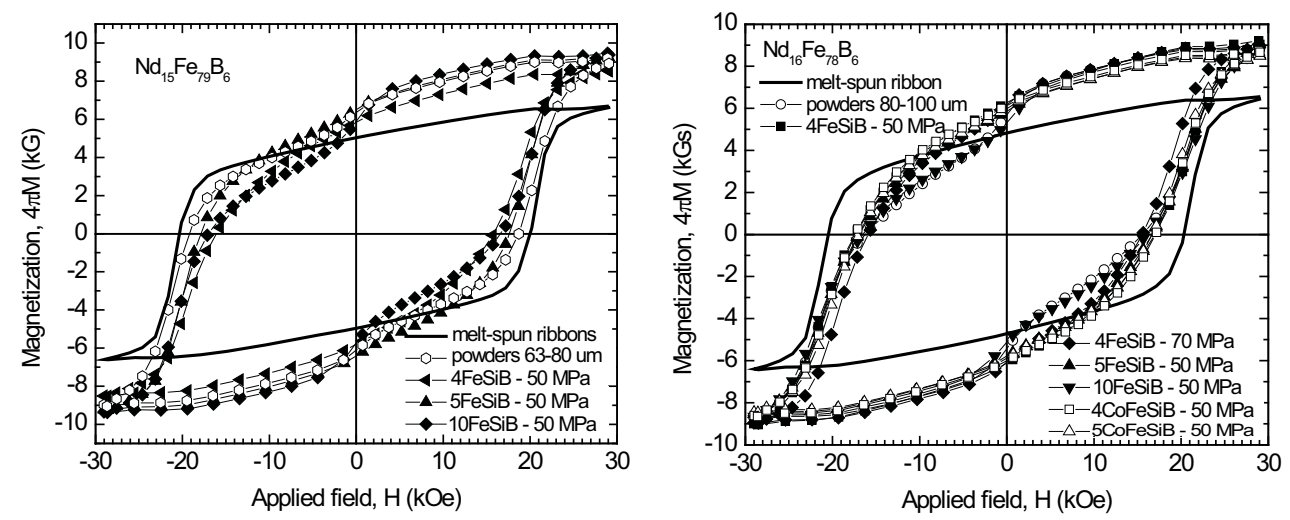

Fig. 12. Magnetic hysteresis loops for Nd-Fe-B nanocomposite SPS magnets. The M-H loops for Nd15 and Nd16 melt-spun ribbons and precursor ball-milled powders are also plotted for comparison.

In Fig. 13 are presented the $\delta M$ curves for $\mathrm{Nd} 15 / \mathrm{FeSiB}$ and Nd15/CoFeSiB SPS nanocomposites with different contents of soft magnetic material. The magnets with less soft magnetic component show larger $\delta \mathrm{M}$ values, i.e. stronger exchange interactions between the nanograins, confirming the large values of the remanence and maximum energy product presented in Table 3. 


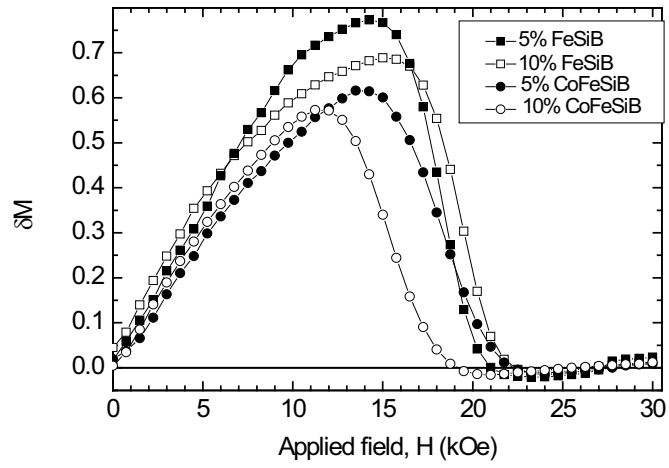

Fig. 13. $\delta \mathrm{M}$ curves for $\mathrm{Nd}_{15} \mathrm{Fe}_{79} \mathrm{~B}_{6} / \mathrm{FeSiB}$ and $\mathrm{Nd}_{15} \mathrm{Fe}_{79} \mathrm{~B}_{6} / \mathrm{CoFeSiB}$ SPS nanocomposite magnets as a function of the soft magnetic component content. Powders with sizes ranging from 63 to $80 \mu \mathrm{m}$ were used to prepare the magnets and a pressure of $50 \mathrm{MPa}$ was applied during SPS process.

The sintering pressure not only displaces the powders to fill the empty spaces but introduces also some frictions between particles. The generated heat during the filling of the empty volume as well as the heat generated through Joule effect when the electrical current is passing through the sample and the local discharges between particles will melt superficially the particles external surface, but due to the very short time of pressing and passing the current through the powders mixture the melt will solidify rapidly and will assure a very strong bonding between the particles. In this way, large density nanocomposite magnets are produced.

Table 4 presents the magnetic characteristics of nanocrystalline FINEMET and amorphous CoFeMnSiB melt-spun ribbons as well as for the Nd-Fe-B/FINEMET and Nd-Fe$\mathrm{B} / \mathrm{CoFeMnSiB} \mathrm{SPS}$ nanocomposite magnets. The magnetic properties of the SPS magnets are altered slightly compared with the Nd16 precursor powders due most probably by the mechanical deformations induced during SPS processing. Once the amount of FINEMET powders is increasing, the saturation magnetization increases because of the higher saturation value of FINEMET compared with Nd16 powders, whilst when increasing the $\mathrm{CoFeMnSiB}$ content the situation is opposite due to the lower saturation magnetization of Co-based amorphous alloy. However, the largest values for the coercive field and the maximum energy product are obtained for Nd16/CoFeMnSiB SPS magnets, as a consequence of the stronger exchange interactions between the nanograins of the soft amd hard magnetic phases. For both types of SPS nanocomposite magnets the optimum magnetic properties are obtained for a sintering pressure of $60 \mathrm{MPa}$.

The coercive field is determined by two main factors: (1) the pinning of the domain walls and (2) the nucleation of the reversed magnetic domains. The simultaneous presence of the two mechanisms is confirmed by the shape of the first magnetization curve for Nd16/FINEMET SPS magnets prepared at two different sintering pressures and shown in Fig. 14. For the SPS magnets sintered at $50 \mathrm{MPa}$ the coercive field is mainly determined by the nucleation mechanism, whereas for the larger sintering pressure of $60 \mathrm{MPa}$ the pinning mechanism becomes predominant. 


\begin{tabular}{|c|c|c|c|c|}
\hline Sample & ${ }_{\mathrm{i}} \mathrm{H}_{\mathbf{c}}(\mathbf{k O e})$ & $4 \pi \mathbf{M}_{3 T}(k G)$ & $4 \pi \mathbf{M}_{\mathbf{r}}(\mathbf{k G})$ & $(\mathrm{BH})_{\max }(\mathrm{MGOe})$ \\
\hline FINEMET ribbons & $1.5 \times 10^{-3}$ & 12.2 & 9.5 & -- \\
\hline CoFeSiBMn ribbons & $5.0 \times 10^{-3}$ & 6.7 & 5.2 & -- \\
\hline $\mathrm{Nd}_{16} \mathrm{Fe}_{78} \mathrm{~B}_{6}$ ribbons & 20.0 & 8.9 & 6.9 & 11.9 \\
\hline NdFeB-4FINEMET / 50MPa & 18.0 & 9.0 & 6.0 & 9.0 \\
\hline NdFeB-4FINEMET / 60MPa & 18.5 & 9.0 & 6.3 & 9.9 \\
\hline NdFeB-5FINEMET / 50MPa & 17.7 & 9.1 & 6.2 & 9.6 \\
\hline NdFeB-5FINEMET / 60MPa & 18.0 & 9.1 & 6.3 & 9.9 \\
\hline NdFeB-6FINEMET / 50MPa & 18.5 & 9.2 & 6.0 & 9.0 \\
\hline NdFeB-6FINEMET / 60MPa & 18.0 & 9.2 & 5.9 & 8.7 \\
\hline NdFeB-4CoFeMnSiB / 50MPa & 17.2 & 8.7 & 6.0 & 9.0 \\
\hline NdFeB-4CoFeMnSiB / 60MPa & 19.5 & 8.4 & 6.1 & 9.3 \\
\hline NdFeB-5CoFeMnSiB / 50MPa & 16.8 & 8.5 & 5.9 & 8.7 \\
\hline NdFeB-5CoFeMnSiB / 60MPa & 18.2 & 8.8 & 6.4 & 10.2 \\
\hline NdFeB-6CoFeMnSiB / 50MPa & 19.5 & 8.7 & 6.2 & 9.6 \\
\hline NdFeB-6CoFeMnSiB / 60MPa & 17.7 & 8.7 & 6.3 & 9.9 \\
\hline
\end{tabular}

Table 4. Magnetic characteristics for nanocrystalline FINEMET and Nd16 ribbons, CoFeMnSiB amorphous ribbons as well as for SPS nanocomposite magnets prepared by combining the Nd16 hard magnetic and FINEMET or Co-based soft magnetic powders.

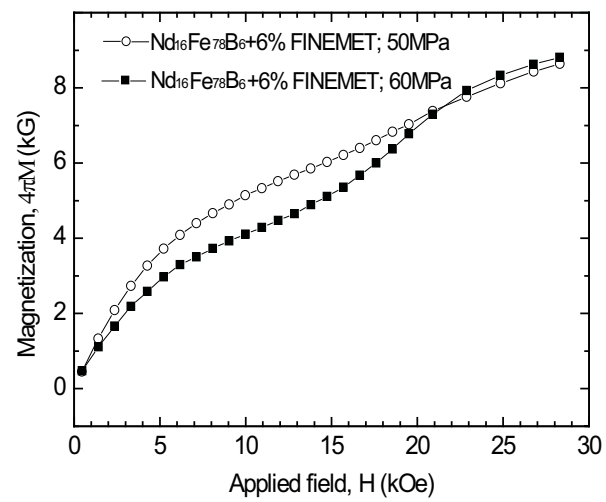

Fig. 14. The first magnetization curves for Nd16-6\%FINEMET SPS magnets sintered at 2 different sintering pressures.

In Fig. 15 are presented comparatively the hysteresis loops for Nd16/FINEMET and $\mathrm{Nd} 16 / \mathrm{CoFeMnSiB} \mathrm{SPS} \mathrm{nanocomposite} \mathrm{magnets} \mathrm{sintered} \mathrm{at} \mathrm{the} \mathrm{same} \mathrm{sintering} \mathrm{pressure} \mathrm{(60}$ $\mathrm{MPa})$. The remanence and coercive field for the 2 nanocomposite magnets are almost the same, but the presence of the shoulder in the second quadrant is almost not visible for the $\mathrm{Nd} 16 / \mathrm{CoFeMnSiB}$ magnets because of the better exchange coupling of the soft and hard magnetic phases.

Fig. 16 shows the backscattered SEM micrographs of Nd16/5Fe SPS magnets consolidated at two pressures: $50 \mathrm{MPa}(\mathrm{a})$ and $80 \mathrm{MPa}(\mathrm{b})$. One can notice the difference in the morphologies of the two magnets and the fact that higher pressures are melting the powders 


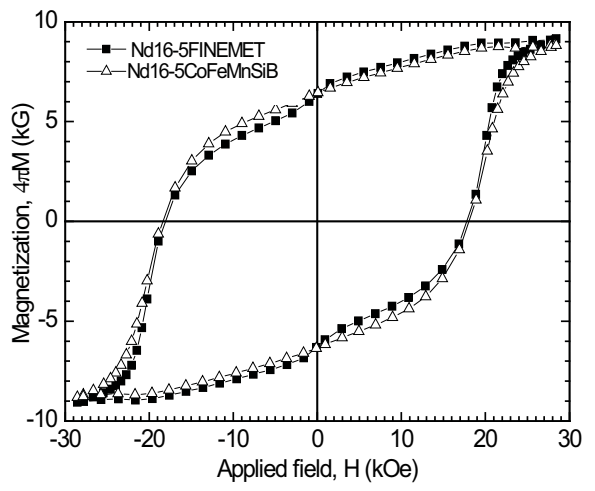

Fig. 15. Magnetic hysteris loops for Nd16/FINEMET and Nd16/CoFeMnSiB SPS nanocomposite magnets sintered at $60 \mathrm{MPa}$.

boundaries and the resulting material is similar with a bulk one. Both magnets prepared at 50 and $80 \mathrm{MPa}$, respectively, are mainly consisting of primary $\mathrm{Nd}_{2} \mathrm{Fe}_{14} \mathrm{~B}$ hard magnetic phase and secondary aFe soft magnetic phase, as proved by XRD patterns shown in Fig. 8 .
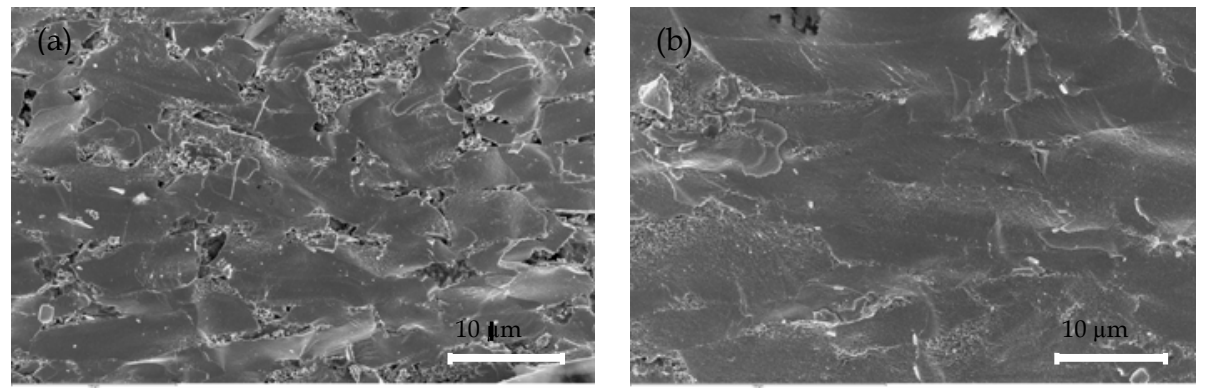

Fig. 16. BSE-SEM micrographs of Nd16Fe78B6+5 wt. \% Fe SPS magnets consolidated at: (a) $50 \mathrm{MPa}$ and (b) $80 \mathrm{MPa}$.

The magnetic characteristics of Nd-Fe-B/Fe SPS nanocomposite magnets are shown in Table 5. The remanence increases from $6.4 \mathrm{kG}$ for Nd15 SPS magnets without addition of Fe to 6.6 $\mathrm{kG}$ for Nd15/5 wt.\% Fe SPS magnets consolidated at the same pressure of $50 \mathrm{MPa}$. Further increase of Fe powders content leads to the decrease of the remanence to $5.6 \mathrm{kG}$ for Nd15/10 wt. $\%$ Fe SPS magnets consolidated at $50 \mathrm{MPa}$. The enhancement of the remanence of the SPS nanocomposite magnets comes from the exchange interactions between the powders of the hard and soft magnetic phases, respectively. The increase of the Fe powders content leads to a slight decrease of the coercivity, too. A more evident proof of the increasing role of exchange interactions in SPS nanocomposite magnets appears when comparing the meltspun ribbons, the precursor powders and the SPS samples. Whereas in the ribbons the coupling between the grains of the hard and soft magnetic phases is very good, it is deteriorating for the powders and the decoupling shoulder appears on the $\mathrm{M}-\mathrm{H}$ loops. The decoupling is becoming less evident for SPS nanocomposite magnets with 4 and $5 \mathrm{wt}$ \% $\mathrm{Fe}$, and is reappearing for larger contents of Fe powders. The coercive field also increases with the Fe powders content to $5 \mathrm{wt}$ \%, reaching almost the value obtained for melt-spun ribbons 
in the as-quenched state. A similar behaviour is observed for Nd16 SPS consolidated magnets. The magnetic properties are altered for all SPS nanocomposite magnets consolidated at higher pressures $(80 \mathrm{MPa})$. Correlating the microstructure evolution with the observed changes in their magnetic properties, the alteration could be determined by the effect of both the distance modification between particles and their deformation (see Fig. 16, too). By consolidation through the SPS technique the maximum energy product generally increases for optimal processing parameters, the highest increase of about $8 \%$ being obtained for Nd15/5 wt.\% Fe SPS nanocomposite magnets consolidated at $50 \mathrm{MPa}$ compared with the similar Nd15 SPS magnets prepared in the same conditions.

\begin{tabular}{|c|c|c|c|}
\hline Sample & ${ }_{\mathrm{i}} \mathrm{H}_{\mathrm{c}}(\mathrm{kOe})$ & $4 \pi \mathbf{M}_{r}(\mathbf{k G})$ & $(\mathrm{BH})_{30 \mathrm{G}}$ (MGOe) \\
\hline \multicolumn{4}{|l|}{$\mathrm{Nd}_{15} \mathrm{Fe}_{79} \mathrm{~B}_{6}$} \\
\hline Nd15 / 50MPa & 17.8 & 6.4 & 10.2 \\
\hline Nd15-4Fe / 50MPa & 17.4 & 6.6 & 10.9 \\
\hline Nd15-4Fe / 80MPa & 17.2 & 6.4 & 10.2 \\
\hline Nd15-5Fe / 50MPa & 18.1 & 6.6 & 10.9 \\
\hline Nd15-5Fe / 80MPa & 17.2 & 6.5 & 10.6 \\
\hline Nd15-10Fe / 50MPa & 16.8 & 6.0 & 9.0 \\
\hline Nd15-10Fe / 80MPa & 15.8 & 5.6 & 7.8 \\
\hline \multicolumn{4}{|l|}{$\mathrm{Nd}_{16} \mathrm{Fe}_{78} \mathrm{~B}_{6}$} \\
\hline Nd16 / 50MPa & 17.5 & 6.1 & 9.3 \\
\hline Nd16-4Fe / 50MPa & 17.4 & 6.4 & 10.2 \\
\hline Nd16-4Fe / 80MPa & 16.7 & 6.2 & 9.6 \\
\hline Nd16-5Fe / 50MPa & 16.7 & 6.4 & 10.2 \\
\hline Nd16-5Fe / 80MPa & 16.5 & 5.9 & 8.7 \\
\hline Nd16-10Fe / 50MPa & 15.5 & 6.2 & 9.6 \\
\hline Nd16-10Fe / 80MPa & 15.0 & 5.9 & 8.7 \\
\hline
\end{tabular}

Table 5. Magnetic characteristics for Nd15, Nd16, Nd15/Fe and Nd16/Fe SPS nanocomposite magnets.

Fig. 17 presents comparatively the $\delta M$ curves for Nd15/Fe SPS nanocomposite magnets consolidated at $50 \mathrm{MPa}$. When the applied field is small and the nanocomposite magnet is in the initial magnetization state the magnetic moments within the nanograins are randomly oriented and the distribution of angles between adjacent moments is broad. Hence, there are exchange interactions between nanograins and $\delta M$ has positive values (the ascending part of the $\delta \mathrm{M}$ plots). The increase of the applied field favors the alingnment of the neighboring magnetic moments in the nanograins and the exchange interactions become predominant. Consequently, $\delta \mathrm{M}$ increases and reaches a peak. The shift of the maximum field value to larger fields for $4 \mathrm{wt}$.\% Fe and $5 \mathrm{wt}$ \% SPS nanocomposite magnets is also consistent with the increase in coercivity (Table 5). Additionally, a higher $\delta \mathrm{M}$ peak indicates stronger exchange interactions between the nanograins of the magnetically hard and soft phases. The strongest exchange interactions are observed for a content of $5 \mathrm{wt}$ \% Fe. While the applied field approaches the coercivity (Fig. 17 and Table 5), the moments basically cancel out each other and the effective magnetization in the direction of applied field approximates to zero. Thus, the magnetostatic interactions are still very weak and the exchange interactions are 
predominant giving positive $\delta \mathrm{M}$ values. With the continuous increase of the applied field the magnetic moments are gradually aligned parallel in each grain and the dipolar interactions between nanograins are becoming more important compared with the exchange interactions. Consequently, $\delta \mathrm{M}$ becomes slightly negative.

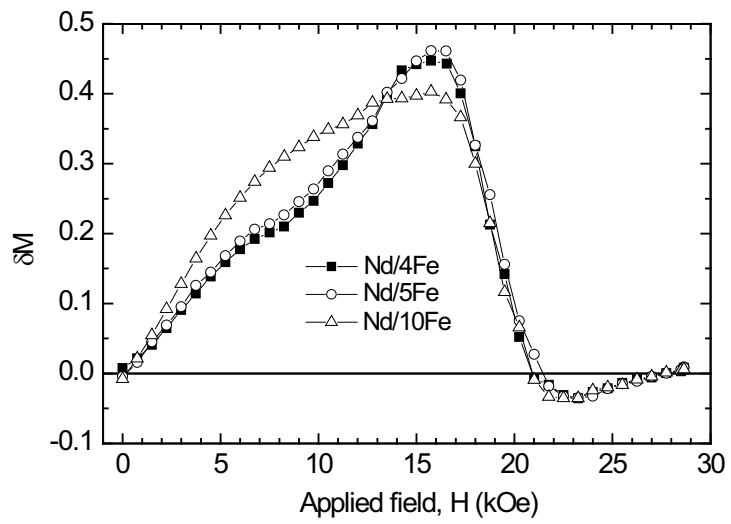

Fig. 17. $\delta \mathrm{M}$ plots for Nd15/Fe SPS nanocomposite magnets consolidated at $50 \mathrm{MPa}$.

M-H loops for Nd16/FeCo SPS nanocomposite magnets presented in Fig. 18 show that the largest coercive field is reached for $96 \mathrm{Nd} 16: 4 \mathrm{FeCo}$. For this ratio the exchange coupling is the strongest and no decoupling is visible in the second quadrant. By increasing the FeCo content the decoupling between soft and hard magnetic nanograins is evident and the shoulder appearing on the demagnetization curves is more pronounced.

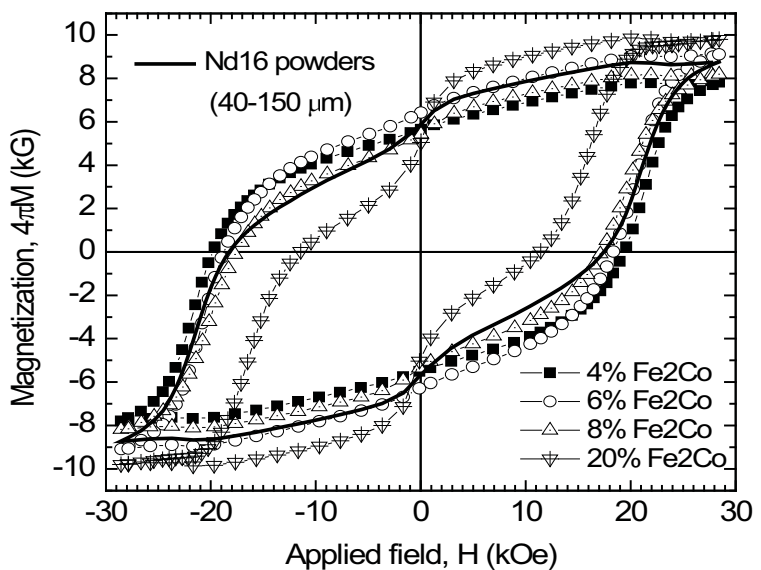

Fig. 18. Magnetic hysteris loops for Nd16/FeCo SPS nanocomposite magnets sintered at 50 $\mathrm{MPa}$. The hystersis loop for the precursor Nd16 powders is shown for comparison.

Whereas the coercive field values are increasing with the increase of $\mathrm{Nd}$ content in the hard magnetic phase precursors, the largest values of the maximum energy product are achieved for Nd12/4FeCo SPS nanocomposite magnets (Table 6). 


\begin{tabular}{|l|c|c|c|c|}
\hline \multicolumn{1}{|c|}{ Sample } & Hc $(\mathbf{k O e})$ & $\mathbf{4} \pi \mathbf{M}_{\mathbf{s}}(\mathbf{k G})$ & $\mathbf{4} \pi \mathbf{M}_{\mathbf{r}}(\mathbf{k G})$ & $\mathbf{( B H}_{\max }$ (MGOe) \\
\hline Nd8-4FeCo & 4.0 & 10.8 & 5.7 & 8.1 \\
\hline Nd8-10FeCo & 3.6 & 13.3 & 7.1 & 12.6 \\
\hline Nd10-4FeCo & 5.2 & 10.1 & 6.2 & 9.6 \\
\hline Nd10-10FeCo & 4.7 & 12.8 & 7.2 & 12.9 \\
\hline Nd12-4FeCo & 10.0 & 10.4 & 7.6 & 14.4 \\
\hline Nd12-10FeCo & 8.4 & 11.5 & 6.6 & 10.9 \\
\hline Nd15-4FeCo & 13.0 & 9.1 & 6.5 & 10.5 \\
\hline Nd15-10FeCo & 12.0 & 9.6 & 5.5 & 7.6 \\
\hline Nd16-4FeCo & 17.6 & 8.4 & 5.8 & 8.4 \\
\hline Nd16-10FeCo & 13.9 & 9.0 & 5.7 & 8.1 \\
\hline
\end{tabular}

Table 6. The magnetic characteristics of Nd-Fe-B/FeCo SPS nanocomposite magnets sintered at $50 \mathrm{MPa}$.

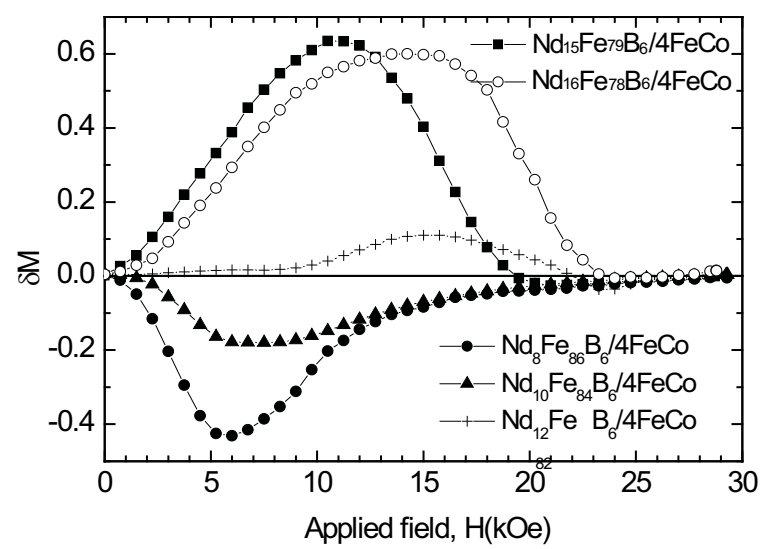

Fig. 19. $\delta \mathrm{M}(\mathrm{H})$ curves as a function of $\mathrm{Nd}$ content in the hard magnetic component precursors. All SPS nanocomposites magnets contain the same amount of $\mathrm{Fe}_{2} \mathrm{Co}$ powders, i.e. $4 \mathrm{wt} . \%$, and they are consolidated at $50 \mathrm{MPa}$.

For nanocomposite magnets with low contents of $\mathrm{Nd}(\mathrm{Nd} 8 / 4 \mathrm{FeCo}$ and $\mathrm{Nd} 10 / 4 \mathrm{FeCo})$ the values of $\delta \mathrm{M}$ shown in Fig. 19 are negative suggesting that the interactions between the soft and hard magnetic nanograins have dipolar (long-range magnetostatic) character and promote the demagnetized state. The magnetostatic interactions reduce the number of irreversible magnetization processes during magnetization in comparison with those occurring during demagnetization. The positive $\delta \mathrm{M}$ curves for Nd-rich (Nd15/4FeCo and $\mathrm{Nd} 16-4 \mathrm{FeCo}$ ) nanocomposite magnets suggest stronger exchange interactions dominating the magnetization processes. $\delta \mathrm{M}$ increases for $\mathrm{Nd} 12 / 4 \mathrm{FeCo}$ nanocomposite magnets and exhibits a peak on the positive side when increasing the applied field, then decreases to zero and changes to negative for much larger applied fields than the coercive field (Fig. 19 and Table 6).

The highest positive peak is obtained for $\mathrm{Nd} 15 / 4 \mathrm{FeCo}$ nanocomposite magnets, suggesting predominant exchange interactions in the detriment of the magnetostatic ones. The same 
behaviour is observed independent of the FeCo content in the Nd-Fe-B/FeCo SPS nanocomposite magnets.

Fig. 20 presents the first magnetization curves for $\mathrm{Nd} 8 / 4 \mathrm{FeCo}, \mathrm{Nd} 10 / 4 \mathrm{FeCo}$ and $\mathrm{Nd} 12 / 4 \mathrm{FeCo}$ SPS nanocomposite magnets sintered at $50 \mathrm{MPa}$.

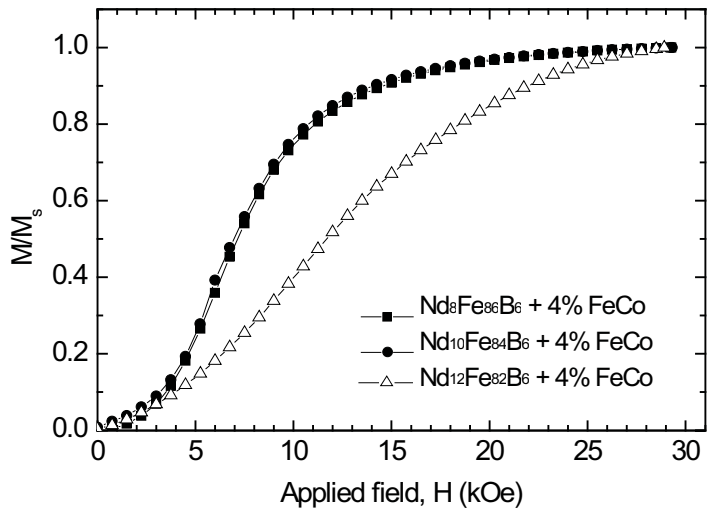

Fig. 20. First magnetization curves for NdFeB/FeCo SPS nanocomposite magnets consolidated at $50 \mathrm{MPa}$.

From the shape of the first magnetization curves we can conclude that for Nd8/4FeCo and $\mathrm{Nd} 10 / 4 \mathrm{FeCo}$ magnets the nucleation of the domain walls with reversed magnetization is predominant, whereas the mechanism is changed to the domain wall pinning for $\mathrm{Nd} 12 / 4 \mathrm{FeCo}$. This is related also to the fact that in $\mathrm{Nd} 12 / 4 \mathrm{FeCo}$ nanocomposite magnets the amount of 2:14:1 phase is larger than for the sub-stoichiometric ( $\mathrm{Nd} 8$ and $\mathrm{Nd} 10$ ) compositions or Nd-rich compositions ( $\mathrm{Nd} 15$ and Nd16). The increase of the sintering temperature from $600^{\circ} \mathrm{C}$ to $650^{\circ} \mathrm{C}$ or of the sintering time from 5 to $7 \mathrm{~min}$. results in the deterioration of the magnetic properties due to the increased amount of soft magnetic phases as well as to the increase of the nanograins size from $20-30 \mathrm{~nm}$ to $150-200 \mathrm{~nm}$. A temperature below $600^{\circ} \mathrm{C}$ or a sintering time shorter than $5 \mathrm{~min}$. are not enough for a good bonding between the hard and soft magnetic components, even at a higher sintering pressure of $80 \mathrm{MPa}$. The increase of the sintering pressure from 50 to $80 \mathrm{MPa}$ increases a little bit the remanence, but leaves the coercive field almost constant.

\section{Conclusions and future perspectives}

Nanocomposite permanent magnets have been obtained by SPS consolidation of powders of different hard and soft magnetic materials in different ratios. The powders have been obtained by ball-milling the $\mathrm{NdFeB}$ hard magnetic nanocrystalline melt-spun ribbons precursors and respectively $\mathrm{FeSiB}$ or $\mathrm{CoFeSiB}$ amorphous wires, FINEMET nanocrystalline melt-spun ribbons, $\mathrm{CoFeMnSiB}$ amorphous melt-spun ribbons, $\mathrm{Fe}_{2} \mathrm{Co}$ fully crystalline meltspun ribbons or Fe commercial micropowders.

Despite the fact that the powders exhibit larger coercive fields, the coupling between the soft and hard magnetic phases is improved for nanocomposite magnets. The strength of the decoupling is indicated by the second shoulder of $\mathrm{dM} / \mathrm{dH}=\mathrm{f}(\mathrm{H})$ curves located nearby $\mathrm{Y}$ 
axis, which is very small for SPS consolidated nanocomposite magnets. Most probably a collective process of both exchange and magnetostatic interactions between the powders of the 2 materials forming the nanocomposite is responsible for such specific behaviour. The exchange coupling plays the predominant role in Nd-Fe-B melt-spun nanocrystalline ribbons, whereas the magnetostatic interactions becomes more predominant for Nd-rich nanocomposites. However, the percentage of exchange interactions contribution to the macroscopic response of the nanocomposite systems is still very important, considering that usually the magnetostatic interactions are reducing the coercive field values.

The magnetic properties can be tailored by choosing the proper SPS consolidation conditions and the optimum ratios of the 2 or more different phases forming the nanocomposites.

Further studies on increasing the amount of soft magnetic component and the sintering pressure are necessary to increase the maximum energy product and to reach at least the values obtained for existing sintered magnets (maximum 55 MGOe), if not the calculated ones (64 MGOe) (Sagawa et al., 1985). To achieve this goal, the preparation of anisotropic SPS nanocomposite magnets consisting of Nd-Fe-B hard magnetic and Fe or Co-Fe based soft magnetic materials is imperiously necessary. Another goal is to increase the operating temperature of these magnets from $100-150^{\circ} \mathrm{C}$ to at least $250-300^{\circ} \mathrm{C}$ by adding to the Nd-Fe-B hard magnetic component Co-based materials or other additives which could increase the Curie temperature of these SPS nanocomposite PMs.

\section{Acknowledgments}

Support from the Romanian Nucleu Programme (Project PN 09-43 02 01) is highly acknowledged.

\section{References}

Ao, Q., Zhang, W. \& Wu, J. (2005). Perpendicular magnetic anisotropy in nanocomposite Nd-Fe-B/FeCo bilayer films. Scripta Materialia, Vol. 52, No. 12 (June 2005) 12471251

Betancourt, I. \& Davies, H.A. (2010). Exchange coupled nanocomposite hard magnetic alloys. Materials Science and Technology, Vol. 26, No. 1 (January 2010) 5-19

Bhame, S.D.; Swaminathan, V.; Deheri, P.K. \& Ramanujan, R.V. (2010). Exchange coupled $\mathrm{Nd} 2 \mathrm{Fe} 14 \mathrm{~B} /$ alpha-Fe nanocomposite by novel autocombustion-reduction diffusion synthesis. Advanced Science Letters, Vol. 3, No. 2 (June 2010) 174-179

Cha, H.; Kim, C.; Ji, E.; Kim, Y.; Jadhav, A.; Kang, D. \& Kang, Y. (2010). Enhanced exchangecoupling effect in Nd-Fe-B/Fe-B nanocomposite magnet. eburnal of Nanoscience and Nanotechnology, Vol. 10, No. 1 (January 2010) 186-190

Chiriac, H.; Vinai, F.; Ovari, T.A.; Marinescu, C.S.; Barariu, F. \& Tiberto, P. (1997). Comparative study of the giant magneto-impedance effect in CoFeSiB magnetic amorphous ribbons and wires. Materials Science and Engineering A-Structural Materials Properties Microstructure and Processing, Vol. 226-228, (15 June 1997) 646649 
Chiriac, H.; Ovari, T.A.; Vazquez, M. \& Hernando, A. (1998). Magnetic hysteresis in glasscovered and water-quenched amorphous wires. eburnal of Magnetism and Magnetic Materials, Vol. 177-181, Part 1 (January 1998) 205-206

Croat, J.J.; Herbst, J.F.; Lee, R.W. \& Pinkerton, F.E. (1984). High-energy product Nd-Fe-B permanent magnets. Applied Physics Letters, Vol. 44, No. 1 (1 January 1984) 148-149

Cui, B.Z. \& O'Shea, M.J. (2004). Hard magnetic properties of rapidly annealed NdFeB/Co films and intergrain interactions. eburnal of Magnetism and Magnetic Materials, Vol. 279, No. 1 (August 2004) 27-35

Cui, B.Z.; Yu, C.T.; Han, K.; Liu, J.P.; Garmestani, H.; Pechan, M.J. \& Schneider-Muntau, H.J. (2005). Magnetization reversal and nanostructure refinement in magnetically annealed $\mathrm{Nd}_{2} \mathrm{Fe}_{14} \mathrm{~B} / \mathrm{a}$-Fe-type nanocomposites. eburnal of Applied Physics, Vol. 97, No. 10 (15 May 2005) 10F308

Durst, K.D. \& Kronmüller, H. (1987). The coercive field of sintered and melt-spun NdFeB magnets. eburnal of Magnetism and Magnetic Materials, Vol. 68, No. 1 (1 August 1987) 63-75

Folks, L.; Street, R.; Woodward, R.C.; Hirosawa, S. \& Kanekiyo, H. Magnetic properties of novel resin-bonded exchange coupled rare-earth magnets. eburnal of Magnetism and Magnetic Materials, Vol. 147, No. 3 (June 1995) 360-366

Fukagawa, T.; Ohkubo, T.; Hirosawa, S. \& Hono, K. (2010). Nano-sized disorders in hard magnetic grains and their influence on magnetization reversal at artificial $\mathrm{Nd} / \mathrm{Nd}_{2} \mathrm{Fe}_{14} \mathrm{~B}$ interfaces. eburnal of Magnetism and Magnetic Materials, Vol. 322, No. 21 (November 2010) 3346-3350

Gabay, A.M.; Marinescu, M. \& Hadjipanayis, G.C. (2006). Enhanced $M_{r}$ and (BH) $\max$ in anisotropic $\mathrm{R}_{2} \mathrm{Fe}_{14} \mathrm{~B} / \alpha$-Fe composite magnets via intergranular magnetostatic coupling. eburnal of Applied Physics, Vol. 99, No. 8 (15 April 2006) 08 B506

Givord, D.; Li, H.S. \& Moreau, J.M. (1984). Magnetic properties and crystal structure of $\mathrm{Nd}_{2} \mathrm{Fe}_{14}$ B. Solid State Communications, Vol. 50, No. 6 (May 1984) 497-499

Hadjipanayis, G.C.; Hazelton, R.C. \& Lawless, K.R. (1984). Cobalt-free permanent magnet materials based on iron-rare-earth alloys. eburnal of Applied Physics, Vol. 55, No. 6 (15 March 1984) 2073-2077

Hadjipanayis, G.C. (1999). Nanophase hard magnets. eburnal of Magnetism and Magnetic Materials, Vol. 200, No. 1-3 (October 1999) 373-391

Hilzinger, H.R. \& Kunz, W. (1980). Magnetic properties of amorphous alloys with low magnetostriction. eburnal of Magnetism and Magnetic Materials, Vol. 15-18, Part 3 (January-March 1980) 1357-1358

Jha, A. \& Davies, H.A. (1989). Kinetics of crystallization of rapidly quenched FeNdB alloy and its application in the processing of permanent magnets. eburnal of NonCrystalline Solids, Vol. 113, No. 2-3 (4 December 1989) 185-194

Kaneko, Y.; Kuniyoshi, F. \& Ishigaki, N. (2006). Proven technologies on high-performance Nd-Fe-B sintered magnets. eburnal of Alloys and Compounds, Vol. 408-412 ((9 February 2006) 1344-1349

Kato, H.; Ishizone, M.; Koyama, K. \& Miyazaki, T. (2005). Realization of anisotropic nanocomposite magnet in $\mathrm{Nd}_{2} \mathrm{Fe}_{14} \mathrm{~B} /$ alpha-Fe thin films. eburnal of Magnetism and Magnetic Materials, Vol. 290, Part 2 (April 2005) 1221-1225 
Kneller, E.F. \& Hawig R. (1991). The exchange-spring magnet: A new materials principle for permanent magnets. IEEE Transactions on Magnetics, Vol. 27, No. 4 (July 1991) 35883600

Lewis, L.H.; Moodenbaugh, A.R.; Welch, D.O. \& Panchanathan, V. (2001). Stress, strain and technical magnetic properties in 'exchange-spring' $\mathrm{Nd}_{2} \mathrm{Fe}_{14} \mathrm{~B}+\mathrm{alpha}-\mathrm{Fe}$ nanocomposite magnets. eburnal of Physics D-Applied Physics, Vol. 34, No. 5 (7 March 2001) 744-751

Liu, Z.G.; Umemoto, M.; Hirosawa, S. \& Kanekiyo, H. (1999). Spark plasma sintering of NdFe-B magnetic alloy. eburnal of Materials Research, Vol. 14, No. 6 (June 1999) 25402547

Liu, Z.W.; Ramanujan, R.V.; Davies, H.A. (2008). Improved thermal stability of hard magnetic properties in rapidly solidified RE-TM-B alloys. eburnal of Materials Research, Vol. 23, No. 10 (October 2008) 2733-2742

Lupu, N.; Grigoras, M.; Lostun, M. \& Chiriac, H. (2009). $\mathrm{Nd}_{2} \mathrm{Fe}_{14} \mathrm{~B} /$ soft magnetic wires nanocomposite magnets with enhanced properties. eburnal of Applied Physics, Vol. 105, No. 7 (1 April 2009) 07A738

Makino, A.; Inoue, A. \& Masumoto T (1990). Compositional effect on the crystallization behaviour of Co-Fe-Si-B amorphous alloys with zero magnetostriction. Materials Transaction, IM, Vol. 31, No. 10 (October 1990) 891-897

Manaf, A.; Buckley, R.A. \& Davies H.A. (1993). New nanocrystalline high-remanence NdFe-B alloys by rapid solidification. eburnal of Magnetism and Magnetic Materials, Vol. 128, No. 3 (December 1993) 302-306

Marinescu, M.; Liu, J.F.; Bonder, M.J. \& Hadjipanayis, G.C. (2008). Fe-nanoparticle coated anisotropic magnet powders for composite permanent magnets with enhanced properties. eburnal of Applied Physics, Vol. 103, No. 7 (1 April 2008) 07E120

McCormick, P.G.; Miao, W.F.; Smith, P.A.I.; Ding, J. \& Street, R. (1998). Mechanically alloyed nanocomposite magnets. eburnal of Applied Physics, Vol. 83, No. 11, Part 2 (1 June 1998) 6256-6261

McGuiness, P.J.; Short, C.; Wilson, A.F. \& Harris, I.R. (1992a). The production and characterization of bonded, hot-pressed and die-upset HDDR magnets. eburnal of Alloys and Compounds, Vol. 184, No. 2 (12 June 1992) 243-255

McGuiness, P.J.; Short, C.L. \& Harris, I.R. (1992b). Anisotropic HDDR epoxy bonded magnets from NdFeBZr. IEEE Transactions on Magnetics, Vol. 28, No. 5, (September 1992) 2160-2162

Mendoza-Suárez, G.; Davies, H.A. \& Escalante-García. J.I. (2000). j $\mathrm{H}_{\mathrm{c}}$, $\mathrm{J}_{\mathrm{r}}$ and (BH) $\max$ relationship in PrFeB melt spun alloys. eburnal of Magnetism and Magnetic Materials, Vol. 218, No. 1 (2 July 2000) 97-102

Niu, P.L.; Yue, M.; Li, Y.L.; Huang, W. \& Zhang, J.X. (2007). Bulk anisotropy Nd-Fe$\mathrm{B} /$ alpha-Fe nanocomposite permanent magnets prepared by sonochemistry and spark plasma sintering. Physica Status Solidi A-Applications and Materials Science, Vol. 204, No. 12 (December 2007) 4009-4012

Ohnaka, I. (1985). Melt spinning into a liquid cooling medium. International eburnal of Rapid Solidification, Vol. 1, No. 3 (1985) 219-236 
Ono, H.; Tayu, T.; Waki, N.; Sugiyama, T.; Shimada, M.; Kanou, M.; Fujiki, A.; Yamamoto, H.; Takasugi, K. \& Tani, M. (2003). Investigation of high saturation magnetization of low rare-earth content alpha- $\mathrm{Fe} / \mathrm{Nd}_{2} \mathrm{Fe}_{14} \mathrm{~B}$ bulk exchange-spring magnets. eburnal of Applied Physics, Vol. 93, No. 7 (1 April 2003) 4060-4065

Onodera, H.; Yamaguchi, Y.; Yamamoto, H.; Sagawa, M.; Matsuura, Y. \& Yamamoto, H. (1984). Magnetic properties of a new permanent magnet based on a Nd-Fe-B compound (NEOMAX). I. Mössbauer study. eburnal of Magnetism and Magnetic Materials, Vol. 46, No. 1-2 (December 1984) 151-156

Pinkerton, F.E. (1991). Microstructure and coercivity of rapidly quenched Nd-FeB magnets. Materials Research Society Symposium Proceedings, Vol. 232 (1991) 249-260

Rada, M.; Lyubina, J.; Gebert, A.; Gutfleisch, O. \& Schultz, L. (2005). Corrosion behavior of $\mathrm{Nd}-\mathrm{Fe}-\mathrm{B} / \mathrm{alpha}-\mathrm{Fe}$ nanocomposite magnets. eburnal of Magnetism and Magnetic Materials, Vol. 290, Part 2 (April 2005) 1251-1254

Sagawa, M.; Fujimura, S.; Togawa, N.; Yamamoto, H. \& Matsuura, Y. (1984). New material for permanent magnets on a base of $\mathrm{Nd}$ and Fe. eburnal of Applied Physics, Vol. 55, No. 6 (15 March 1984) 2083-2087

Sagawa, M.; Fujimara, S.; Yamamoto, H.; Matsuura, Y. \& Hirosawa, S. (1985). Magnetic properties of rare-earth-iron-boron permanent magnet materials. eburnal of Applied Physics, Vol. 57, No. 8 (15 April 1985) 4094-4096

Saito, T. (2001). Production of bulk materials of an $\mathrm{Nd}_{4} \mathrm{Fe}_{77.5} \mathrm{~B}_{18.5}$ alloy and their magnetic properties. IEEE Transactions on Magnetics, Vol. 37, No. 4 (July 2001) 2561-2563

Saito, T.; Takeuchi, T. \& Kageyama, H. (2004). Structures and magnetic properties of Nd-FeB bulk nanocomposite magnets produced by the spark plasma sintering method. eburnal of Materials Research, Vol. 19, No. 9 (September 2004) 2730-2737

Shindo, M.; Ishizone, M.; Kato, H.; Miyazaki, T. \& Sakuma, A. (1996). Exchange-spring behavior in sputter-deposited alpha-Fe/Nd-Fe-B multilayer magnets. eburnal of Magnetism and Magnetic Materials, Vol. 161 (August 1996) L1-L5

Skomski, R. \& Coey, J.M.D. (1993). Giant energy product in nanostructured two-phase magnets. Physical Review B, Vol. 48, No. 21 (1 December 1993) 15812-15816

Talijan, N.M. (2006). Magnetic properties of sintered high energy Sm-Co and Nd-Fe-B magnets. Science of Sintering, Vol. 38, No. 1 (January-April 2006) 73-82

Tomka, G.J.; Bissell, P.R.; Chantrell, R.W. \& O'Grady, K. (1995). Fluctuation fields in polymer bonded permanent magnets. eburnal of Magnetism and Magnetic Materials, Vol. 140-144, Part 2 (February 1995) 1097-1098

Vazquez, M. \& Chen, D.-X. (1995). The magnetization reversal process in amorphous wires. IEEE Transactions on Magnetics, Vol. 31, No. 2 (March 1995) 1229-1238

Wei, G.; Hadjipanayis, G.C. \& Krause, R.F. (1994). Mechanically alloyed nanocomposite magnets. eburnal of Applied Physics, Vol. 75, No. 10, Part 2B (15 May 1994) 6649-6651

Wohlfarth, E.P. (1958). Relations between different modes of acquisition of the remanent magnetization of ferromagnetic particles. eburnal of Applied Physics, Vol. 29, No. 3 (1 March 1958) 595-596

Yamauchi, H.; Hiroyoshi, H.; Yamaguchi, Y.; Yamamoto, H.; Sagawa, M.; Matsuura, Y. \& Yamamoto, H. (1985). Magnetic properties of a new permanent magnet based on 
Nd-Fe-B compound II. Magnetization. eburnal of Magnetism and Magnetic Materials, Vol. 49, No. 1-2 (March 1985) 210-214

Yoshizawa, Y.; Oguma, S. \& Yamauchi, K. (1988). New Fe-based soft magnetic-alloys composed of ultrafine grain-structure. eburnal of Applied Physics, Vol. 64, No. 10, Part 2 (15 November 1988) 6044-6046

Yue, M.; Zhang, J.; Xiao, Y.; Wang, G. \& Li, T. (2003). New kind of NdFeB magnet prepared by spark plasma sintering. IEEE Transactions on Magnetics, Vol. 39, No. 6 (November 2003) 3551 - 3553

Zhang, X.H. \& Xiong, W.H. (2009). Effect of bonding process on the properties of isotropic epoxy resin-bonded Nd-Fe-B magnets. Rare Metals, Vol. 28, No. 3 (June 2009) 248252 


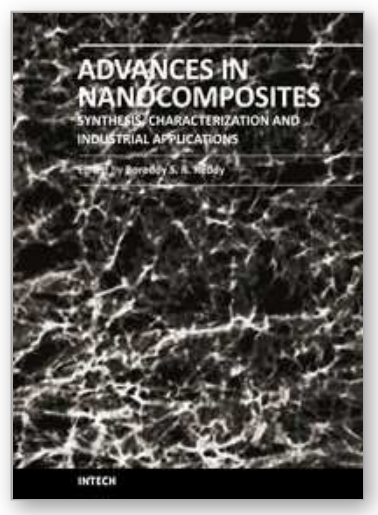

\author{
Advances in Nanocomposites - Synthesis, Characterization and \\ Industrial Applications
}

Edited by Dr. Boreddy Reddy

ISBN 978-953-307-165-7

Hard cover, 966 pages

Publisher InTech

Published online 19, April, 2011

Published in print edition April, 2011

Advances in Nanocomposites - Synthesis, Characterization and Industrial Applications was conceived as a comprehensive reference volume on various aspects of functional nanocomposites for engineering technologies. The term functional nanocomposites signifies a wide area of polymer/material science and engineering, involving the design, synthesis and study of nanocomposites of increasing structural sophistication and complexity useful for a wide range of chemical, physicochemical and biological/biomedical processes. "Emerging technologies" are also broadly understood to include new technological developments, beginning at the forefront of conventional industrial practices and extending into anticipated and speculative industries of the future. The scope of the present book on nanocomposites and applications extends far beyond emerging technologies. This book presents 40 chapters organized in four parts systematically providing a wealth of new ideas in design, synthesis and study of sophisticated nanocomposite structures.

\title{
How to reference
}

In order to correctly reference this scholarly work, feel free to copy and paste the following:

N. Lupu, M. Grigoraş, M. Lostun and H. Chiriac (2011). Spark Plasma Sintered NdFeB-based Nanocomposite Hard Magnets with Enhanced Magnetic Properties, Advances in Nanocomposites - Synthesis, Characterization and Industrial Applications, Dr. Boreddy Reddy (Ed.), ISBN: 978-953-307-165-7, InTech, Available from: http://www.intechopen.com/books/advances-in-nanocomposites-synthesis-characterization-and-industrialapplications/spark-plasma-sintered-ndfeb-based-nanocomposite-hard-magnets-with-enhanced-magneticproperties

\section{INTECH}

open science | open minds

\section{InTech Europe}

University Campus STeP Ri

Slavka Krautzeka 83/A

51000 Rijeka, Croatia

Phone: +385 (51) 770447

Fax: +385 (51) 686166

www.intechopen.com

\section{InTech China}

Unit 405, Office Block, Hotel Equatorial Shanghai

No.65, Yan An Road (West), Shanghai, 200040, China 中国上海市延安西路65号上海国际贵都大饭店办公楼 405 单元

Phone: +86-21-62489820

Fax: $+86-21-62489821$ 
(C) 2011 The Author(s). Licensee IntechOpen. This chapter is distributed under the terms of the Creative Commons Attribution-NonCommercialShareAlike-3.0 License, which permits use, distribution and reproduction for non-commercial purposes, provided the original is properly cited and derivative works building on this content are distributed under the same license. 